\title{
THE DEVELOPMENT OF FLUORIDES FOR HIGH POWER LASER OPTICS
}

Final Report for Period

1 April 1978 - 31 March 1980

\author{
J.F. Ready \\ H. Vora
}

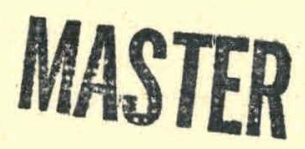

July 1980

WORK PERFORMED UNDER CONTRACT

DE-AC08-78-DP 40020

\section{Honeywell Corporate Material Sciences Center 10701 Lyndale Avenue South \\ Bloomington, Minnesota 55420}




\section{DISCLAIMER}

This report was prepared as an account of work sponsored by an agency of the United States Government. Neither the United States Government nor any agency Thereof, nor any of their employees, makes any warranty, express or implied, or assumes any legal liability or responsibility for the accuracy, completeness, or usefulness of any information, apparatus, product, or process disclosed, or represents that its use would not infringe privately owned rights. Reference herein to any specific commercial product, process, or service by trade name, trademark, manufacturer, or otherwise does not necessarily constitute or imply its endorsement, recommendation, or favoring by the United States Government or any agency thereof. The views and opinions of authors expressed herein do not necessarily state or reflect those of the United States Government or any agency thereof. 


\section{DISCLAIMER}

Portions of this document may be illegible in electronic image products. Images are produced from the best available original document. 


\section{DISCLAIMER}

This report was prepared as an account of work sponsored by the United States Government. Neither the United States nor the United States Department of Energy, nor any of their employees, makes any warranty, express or implied, or assumes any legal liability or responsibility for the accuracy, completeness, or usefulness of any information, apparatus, producl, ur prucess disclosed, or represents that its use would nnt infringe privately owned rights. Reference herein to any specific commcrcial product, process, or service by trade name, mark, manufacturer, or otherwise, does not necessurily cunstitute or imply its cndorsement, recommendation, or favoring by the United States Government or any agency thereof. The views and opinions of authors expressed herein do not necessarily state or reflect those of the United States Government or any agency thereof.

Printed in the United States of America

Available from:

National Technical Information Service

U.S. Department of Commerce

5285 Port Royal Road

Springfield, Virginia 22161

Price: Printed Copy $\$ 6.00$

Microfiche $\$ 3.50$ 
Report DOE/DP/40020-1

Distribution Category UC-21

\title{
THE DEVELOPMENT OF FLUORIDES \\ FOR HIGH POWER LASER OPTICS
}

Final Report for Period

1 April 1978 - 31 March 1980

\author{
J.F. Ready \\ H. Vora \\ Honeywell Corporate Material Sciences Center \\ 10701 Lyndale Avenue South \\ Bloomington, Minnesota 55420
}

Prepared for the

U.S. DEPARTMENT OF ENERGY

Nevada Operations Office

Las Vegas, Nevada 89114

under Contract DE-AC08-78-DP 40020 
THIS PAGE

WAS INTENTIONALLY

LEFT BLANK 


\begin{abstract}
The laser-assisted thermonuclear fusion program has significant needs for improved optical materials with high transmisson in the ultraviolet, and with low values of nonlinear index of refraction. Lithium fluoride $(\mathrm{LiF})$ possesses a combination of optical properties which are of potential use. Single-crystalline LiF is limited by low mechanical strength. In this program, we investigated the technique of press-forging to increase the mechanical strength. LiF single crystals were press-forged over the temperature range $300-600^{\circ} \mathrm{C}$ to produce fine-grained polycrystalline material.
\end{abstract}

'i'he following optical properties' of both single-crystal and press-forged LiF were evaluated in the program: optical homogeneity at $633 \mathrm{~nm}$, stress birefringence, scattering at $633 \mathrm{~nm}$, residual absorption over the spectral range $339-3800 \mathrm{~nm}$, and laser damage thresholds for 1-ns, 1064-nm and 700-ps, 266-nm laser pulses. The results of the optical characterization tasks indicate that LiF single crystals can be press-forged without seriously degrading their optical properties.

The following mechanical properties of both single-crystal and press-forged LiF were evaluated: yield strength in compression, proportional limit and fracture strength in 3and 4-point bending, fracture energy, and threshold for microyield. The results indicate that the mechanical properties of LiF single crystals can be improved significantly by press forging.

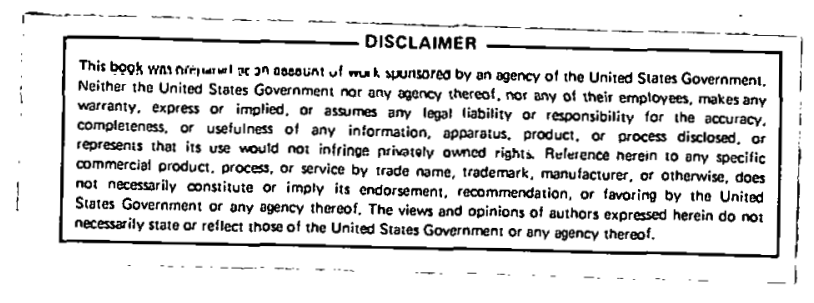

iii

The reverse of this page is blank. 


\section{THIS PAGE}

WAS INTENTIONALLY

LEFT BLANK 


\section{Table of Contents}

Section

1 INTRODUCTION .

2 ISOSTATIC PRESS FORGING 2

2.1 Single-Step Forgings $\quad 8$

- $\quad 2.2$ Two-Step Forgings 11

3 OPTICAL PROPERTIES 16

3.1 Optical Inhomogeneity 16

3.2 Optical Absorption 16

3.3 Stress Birefringence 19

$\begin{array}{ll}3.4 \text { Scattering Profiles } & 19\end{array}$

3.5 Damage Thresholds 25

4 MECHANICAL PROPERTIES $\quad 27$

$\begin{array}{ll}4.1 \text { Yield Strengths } & 27\end{array}$

4.2 Proportional Limit and Fracture Strength 27

4.3 Critical Fracture Energy 29

$\begin{array}{ll}4.4 \text { Microyield Behavior } & 29\end{array}$

$5 \quad$ ENVIRONMENTAL STABILITY 36

6 POLISHING TECHNIQUES

6.1 Sawing $\quad 37$

6.2 Sample Shaping $\quad \cdot 37$

$\begin{array}{ll}6.3 \text { Polishing } & 37\end{array}$

$7 \quad$ FORGING of $\mathrm{KTb}_{\mathbf{3}} \mathrm{F}_{\mathbf{2 0}} \quad 39$

8 SUMMARY $\quad 42$

ACKNOWLEDGEMENTS $\quad 43$

REFERENCES $\quad 45$

DISTRIBUTION LIST 


\section{List of Illustrations}

Figure

Page

1 The strain to fracture of lithium fluoride (LiF) as a

function of temperature.

2 Schematic diagram of isostatic forging apparatus.

3 Photograph of a LiF crystal of $\langle 100\rangle$ orientation polished after forging to $70 \%$ reduction in height.

4 Excessive deformation at any temperature introduces internal cloudiness (veils) in LiF.

$5 \quad$ Photograph of a LiF crystal of $\langle 111\rangle$ orientation forged to.

6 Photograph of a LiF crystal of $\langle 110\rangle$ orientation forged to

7 Microstructure of a $\mathrm{LiF}$ crystal forged at $300^{\circ} \mathrm{C}$ to $30 \%$ reduction in height.

8 Low-angle grain boundaries in a $\mathrm{LiF}$ crystal forged at $400^{\circ} \mathrm{C}$ to $54 \%$ reduction in height.

9 Microstructure of a $\mathrm{LiF}$ crystal forged at $500^{\circ} \mathrm{C}$ to $50 \%$ reduction in height $(110 \mathrm{X})$.

10 Microstructure of a $\mathrm{LiF}$ crystal forged at $600^{\circ} \mathrm{C}$ to $63 \%$ reduction in height.

11 Microstructure of two-step forging H-27 (S-2) (120X).

12 Optical absorption spectra of various $\mathrm{LiF}$ samples.

13 Residual ultraviolet and visible absorption in $\mathrm{LiF}$.

14 Scattering profile of a $5 \mathrm{~mm} \times 5 \mathrm{~mm}$ area of a veiled sample

15 Distribution of scattering signal amplitudes for a veiled sample of press-forged $\mathrm{LiH}^{\prime}$.

16 Orientation of 4-point bend specimen of single-crystal $\mathrm{H}-<110>-4$.

17 Microyield behaviors of single-crystal and press-forged samples H-41.

18 Log-log plot of the microyield data shown in Figure 17. 


\section{List of Illustrations (Concluded)}

Figure

Page

19 Microyield data of single-crystal and press-forged samples $\mathrm{H}-<110>-4$ plotted on a log-log plot.

20 Forged LiF polished with cerium oxide (200X).

$21 \quad$ Forged LiF polished with $0.3 \mu \mathrm{m}$ alumina. $\quad 38$

22 Samples of $\mathrm{KTb}_{3} \mathrm{~F}_{10}$. $\quad 40$

23 Photomicrograph of an etched sample of $\mathrm{KTb}_{3} \mathrm{~F}_{10}$ showing a twin (120X).

24 Photomicrograph of an etched sample of $\mathrm{KTb}_{8} \mathrm{~F}_{10}(60 \mathrm{X})$. 


\section{List of Tables}

Table

$1 \quad$ List of Forged LiF Crystals.

$2 \quad$ Forging Parameters for Various Two-Step Forgings. $\quad 14$

$3 \quad$ Optical Inhomogeneity, Before and After Forging, 17

4 Summary of Ar-ion Laser Calorimetric Data on Single-Crystal and Press-Forged LiF.

$5 \quad$ Laser Calorimetric Dátá at $1.06 \mu \mathrm{m}, 2.7 \mu \mathrm{m}$, and $3.8 \mu \mathrm{m}$ on $\mathrm{LiF}$.

6 Damage Thresholds for 1-ns, 1084 nw Laysr Pulsus fur Single-Crystal and Press-Forged LiF.

7 Damage Thresholds for 700-ps, 266-nm Laser Pulses for Single-Crystal and Press-Forged LiF.

8 Yield Strengths in Compression of Press-Forged LiF.

9 Mechanical Properties of LiF.

10 Microyield, Macroyield, and Fracture Characteristics of LiF. 


\section{Section 1 \\ Introduction}

The laser-assisted thermonuclear fusion program has generated a significant interest in many fluorides, which are characterized by low nonlinear refractive indices, for applications as windows, lenses, and isolators. These materials will be exposed to high-power, short-duration laser pulses, possibly at short wavelengths in the blue or ultraviolet portions of the spectrum. In addition to the requirement of a low value of nonlinear refractive index, which minimizes beam breakup and self focussing, these materials have to meet a number of stringent requirements, including high transmission at ultraviolet wavelengths, resistance to damage by the high-power laser beam, low scattering losses, and high mechanical strength, at least for some applications such as windows for gaseous systems operating at pressures of many atmospheres.

LiF possesses a combination of optical properties which is of interest for window application on such lasers. These properties include a large bandgap for transmission in the visible and ultraviolet, low refractive index for high damage threshold, and a very low value of nonlinear refractive index coefficient $\left(1 \times 10-20 \mathrm{~m}^{2} / \mathrm{W}\right) 1$. Compared to many ionic crystals, $\mathrm{LiF}$ is relatively less soluble in water and possesses a high resistance to attack from moisture present in the atmosphere.

Pure LiF single crystals, while they show excellent transmission in the visible and ultraviolet, are characterized by low yield strength and low fracture energy. Also, the diameter of the largest commercially available LiF crystals appears to be limited to about $15 \mathrm{~cm}$ at the present time. (Requirements for windows $30 \mathrm{~cm}$ or larger in diameter are common for high-power lasers.) The objective of this program is to overcome these shortcomings of LiF crystals without degrading their good optical properties.

Press forging approach has been used successfully in the past to improve mechanical properties and increase the diameter of single crystals of various alkali halides and alkaline earth fluorides. 2,3 In this program, the response of LiF single crystals to press forging has been studied and the effects of press forging on the mechanical and optical properties of $\mathrm{LiF}$ have been evaluated. 


\section{Section 2 \\ Isostatic Press Forging}

In order to arbitrarily change the shape of a crystal with no change in volume during deformation requires five independent shears. This condition is known as von Mises criterion. In a crystal that deforms by glide, the need for five independent shears implies the need for five independent slip systems. In the case of LiF, the primary slip systems, the ones that operate at or near room temperature, are [110] $\langle 1 \overline{1} 0\rangle$, and the secondary slip systems, the ones that operate at elevated temperatures along with the primary systems are $[001]\langle 1 \overline{1} 0\rangle .4$ There are two independent [110] $\langle\overline{1} 10\rangle$ slip systems and three independent [001] $<110>$ slip systems. 5 Since the secondary slip oystems in LiF operate at or above $\sim 400^{\circ} \mathrm{K}, 4$ a temperature of at least $400^{\circ} \mathrm{K}$ is required for the deformation processing of $\mathrm{LiF}$.

One of the earliest studies of the high-temperature mechanical properties of LiF single crystals was made by Phillips. 6 He obtained stress-strain curves at various temperatures for $\langle 100\rangle$ oriented single crystals (dimensions $2.5 \mathrm{~mm} \times 2.5 \mathrm{~mm} \times 7.5 \mathrm{~mm}$ ) deformed in compression and also noted the strain values at various temperatures at which the first macroscopic crack formed in the sample. His strain-to-fracture versus deformation temperature data are shown in Figure 1, where it is seen that the ductility of LiF, although it increases rapidly with increasing temperatures, is limited to 60 percent at $800^{\circ} \mathrm{C}$, which is only $70^{\circ} \mathrm{C}$ below the reported melting point of $\mathrm{LiF} .7$

In order to produce fine-grained materials by press forging, it is considered desirable to employ greater reduction and lower working temperatures. These conditions often form radial cracks during forging. Isostatic forging techniques have been developed to alleviate this problem. In isostatic forging, a high-pressure gas surrounds the crystal to be forged and exerts a compressive hoop stress on it, thereby inhibiting crack initiation and permitting use of lower forging temperatures and larger reductions.

A schematic diagram of the system used for isustulic forging of $\mathrm{LiF}$ is shown in Figure 2. A single-crystal blllet is sandwiched between two graphite plates (not shuwn), one placed on the top of the lower stationary ram and the other between the crystal and the top ram. The downward movement of the upper ram, controlled by a hydraulic pump and monitored by a dial gauge, compresses the crystal, which is heated to the desired temperature by three heating elements, independently controlled and positioned as shown to obtain uniform temperature in the forging region. 


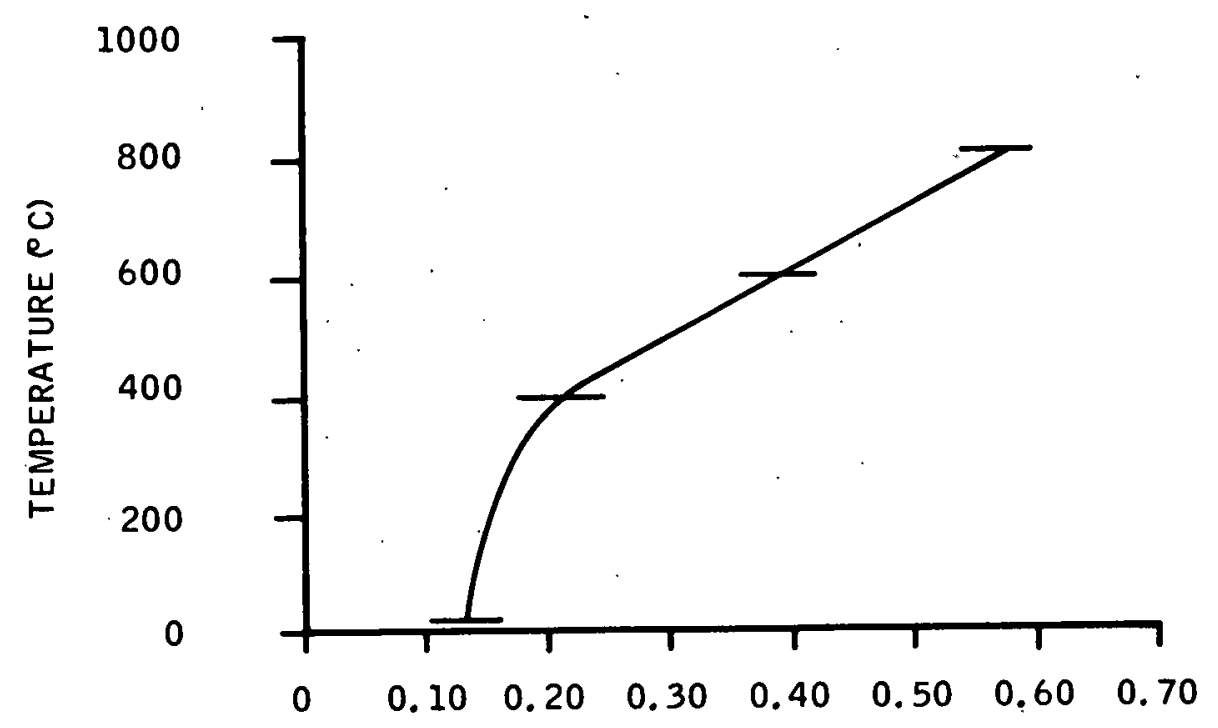

STRAIN TO FRACTURE (IN. IIN.)

Figure 1. The strain to fracture of lithium fluoride (LiF) as a function of temperature.

Most of the LiF crystals used in the present study were right cylinders, $3.2 \mathrm{~cm}$ in diameter and $2.5-3.3 \mathrm{~cm}$ in height, and purchased from the Harshaw Chemical Company. The remaining crystals were also of comparable dimensions and were purchased from the University of Utah and Optovac. Ionic conductivity measurements, made by Professor Thomas G. Stoebe at the University of Washington on a sample cleaved from each starting material indicated an effective concentration of divalent cations of less than 1ppm for both the Harshaw and University of Utah materials and approximately $9 \mathrm{ppm}$ for the Optovac material. Attempts to analyze the content of $\mathrm{Na}, \mathrm{K}, \mathrm{Ba}, \mathrm{Mg}$, and $\mathrm{Ca}$ in the material using atomic absorption spectroscopy were unsuccessful because the low concentrations of these ions were masked by the absorption of $\mathrm{Li}$. The impurity concentrations are in the range of a few parts per million.

Before press forging, each starting crystal was carefully polished with $6 \mu \mathrm{m}$ diamond paste to eliminate any surface imperfections. A typical forging run involved heating the crystal to the desired forging temperature, soaking it at this temperature for about 30 minutes, compressing it to the desired final thickness using a displacement rate of $0.013 \mathrm{~cm} / \mathrm{minute}$ for the top ram, and allowing it to cool to room temperature at a rate of $25-50^{\circ} \mathrm{C}$ /hour after lifting the top ram. All LiF crystals were forged in the presence of a helium atmosphere at $13.8 \mathrm{MN} / \mathrm{m}^{2}$. More than $50 \mathrm{LiF}$ crystals were forged in the program (see Table 1). All of them were observed to be free of radial cracks. Figure 3 shows a photograph of $\mathrm{LiF}$ crystal of $\langle 100\rangle$ orientation which was forged to 70 percent reduction in height and polished. 


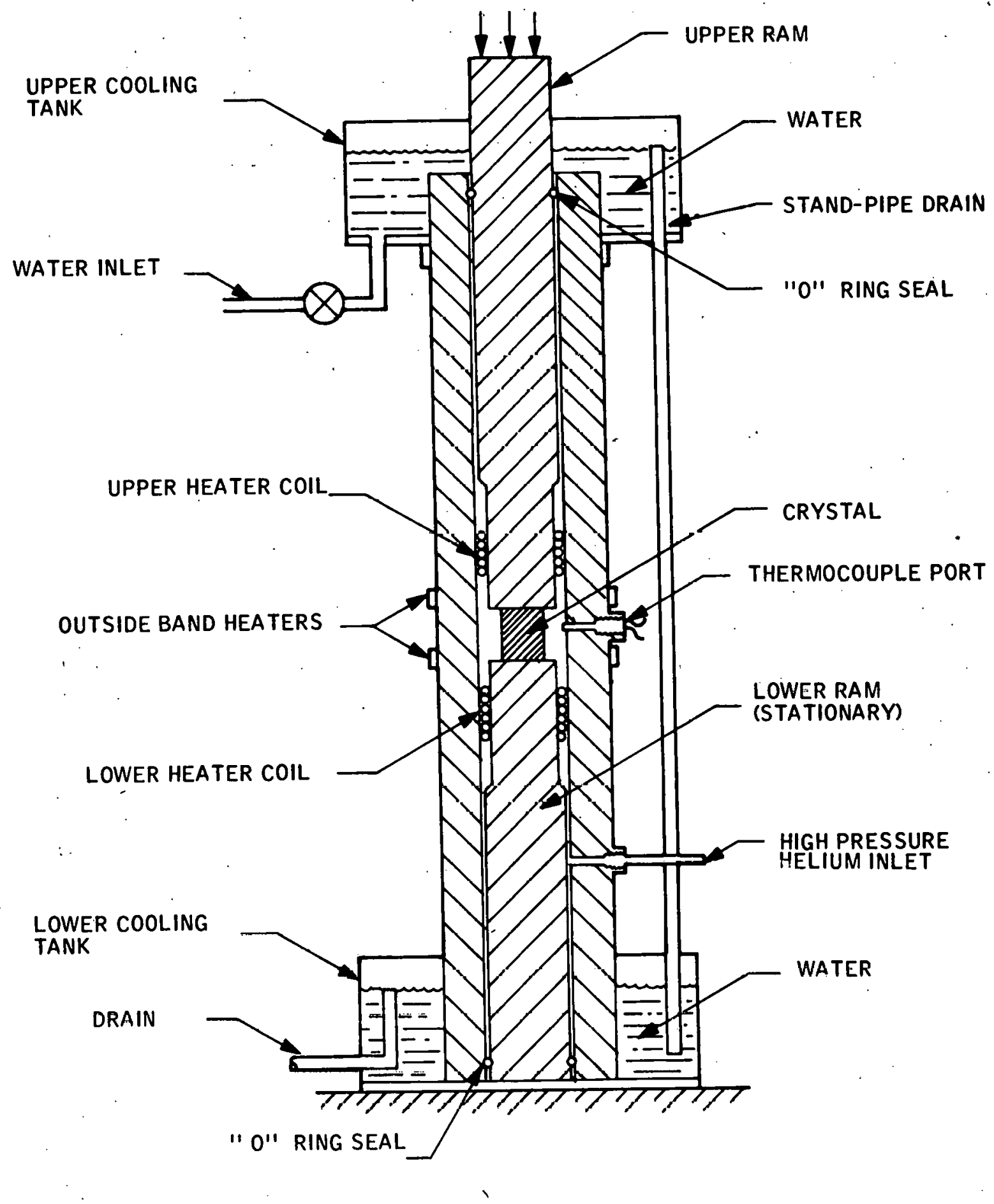

Figure 2. Schematic diagram of isostatic forging apparatus. 
Table 1. List of Forged LiF Crystals.

\begin{tabular}{|c|c|c|c|c|}
\hline Number & Forging & $\begin{array}{l}\text { Forging } \\
\text { Temperature } \\
\left({ }^{\circ} \mathrm{C}\right)\end{array}$ & $\begin{array}{c}\text { Reduction } \\
(\%)\end{array}$ & Comments \\
\hline 1 & U1 & 500 & 48 & \\
\hline 2 & U3 & 500 & 59 & \\
\hline 3 & U4 & 500 & 62 & \\
\hline 4 & U6 & 600 & 63 & \\
\hline 5 & $\mathrm{H} 1$ & 400 & 56 & . \\
\hline 6 & $\mathrm{H} 2$ & 400 & 66 & \\
\hline 7 & H3 & 400 & 71 & \\
\hline 8 & H4 & 400 & 75 & \\
\hline 9 & H5 & 400 & 76 & \\
\hline 10 & $\mathrm{H} 6$ & 400 & 81 & . \\
\hline 11 & $\mathrm{H} 7$ & 400 & 86 & \\
\hline 12 & H8 & 300 & 15 & \\
\hline 13 & H9 & 300 & 26 & \\
\hline 14 & H1O & 300 & 34 & \\
\hline 15 & H11 & 300 & 43 & \\
\hline 16 & $\mathrm{H} 12$ & 400 & 20 & \\
\hline 17 & $\mathrm{H} 13$ & 400 & 30 & : \\
\hline 18 & $\mathrm{H} 14$ & 400 & 38 & \\
\hline 19 & H15 & 400 & 46 & \\
\hline 20 & H16 & 550 & 60 & \\
\hline 21 & $\mathrm{H} 17$ & 550 & 67 & - \\
\hline 22 & H18 & 550 & 71 & 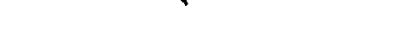 \\
\hline 23 & H19 & 550 & 73 & \\
\hline 24 & $\mathrm{H} 20$ & 600 & 63 & \\
\hline 25 & $\mathrm{H} 21$ & 550 & 60 & $=$ \\
\hline 26 & $\mathrm{H} 22$ & 300 & 30 & \\
\hline 27 & H23 & 400 & 54 & \\
\hline 28 & $\mathrm{H} 24$ & 600 & 72 & \\
\hline 29 & H2J & suU & 50 & \\
\hline 30 & $\mathrm{H} 27$ (SI) & 500 & 45 & \\
\hline \multirow[t]{2}{*}{31} & H27 (SI I )* & 500 & 45 & \\
\hline & . & 500 & 45 . & Overall reduction-70\% \\
\hline \multirow[t]{2}{*}{32} & $\mathrm{H} 28$ (qI)* & 600 & 55 & \\
\hline & & 500 & 45 & Overall reduction- $76 \%$ \\
\hline \multirow[t]{2}{*}{33} & $\mathrm{H} 38$ (qII)* & 400 & 43 & 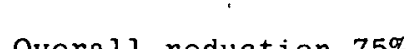 \\
\hline & & 500 & 56 & Uverdil reauction-10\% \\
\hline 34 & H28 (qIII) & 400 & 43 & \\
\hline
\end{tabular}


Table 1. List of Forged LiF Crystals (Concluded).

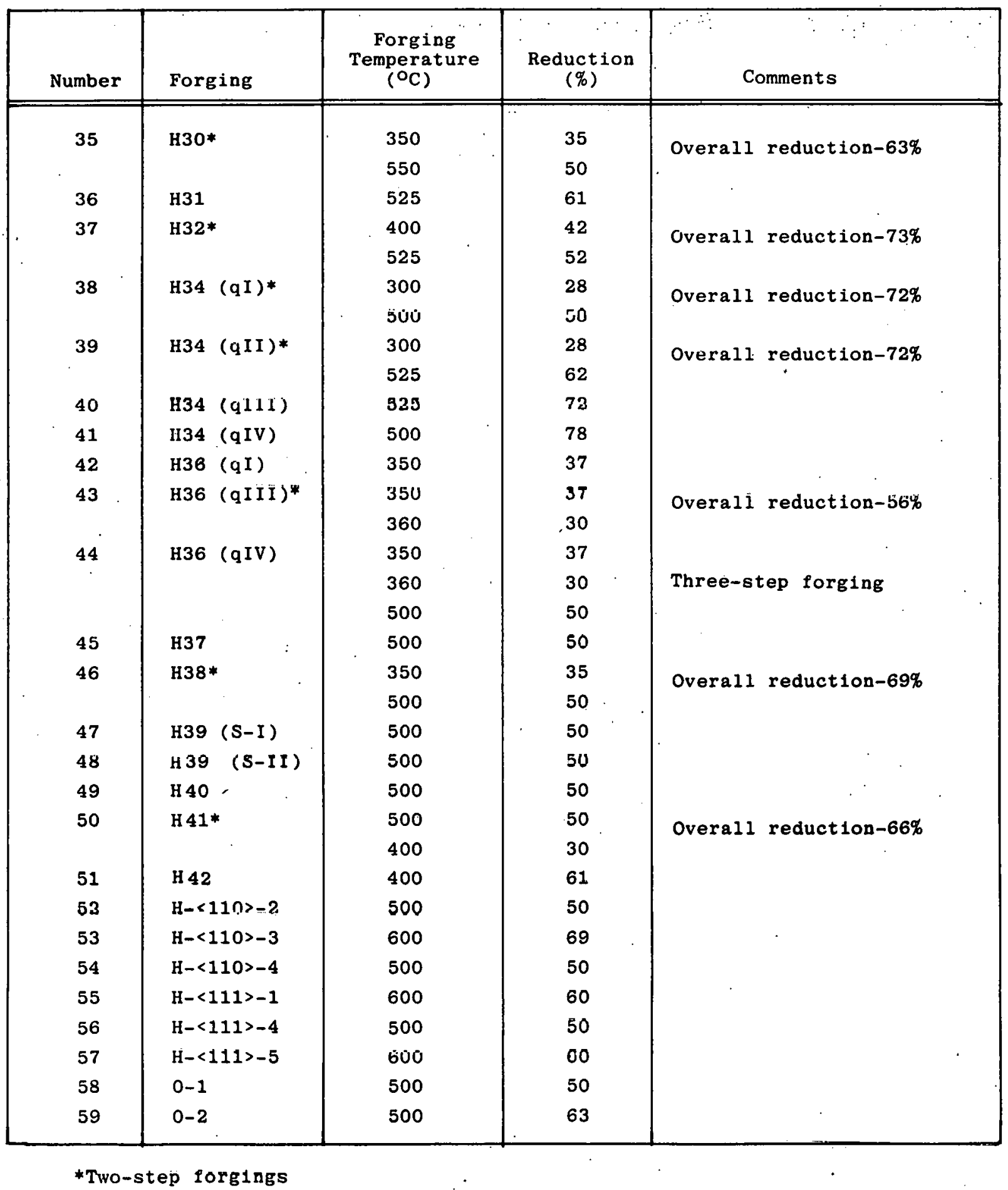




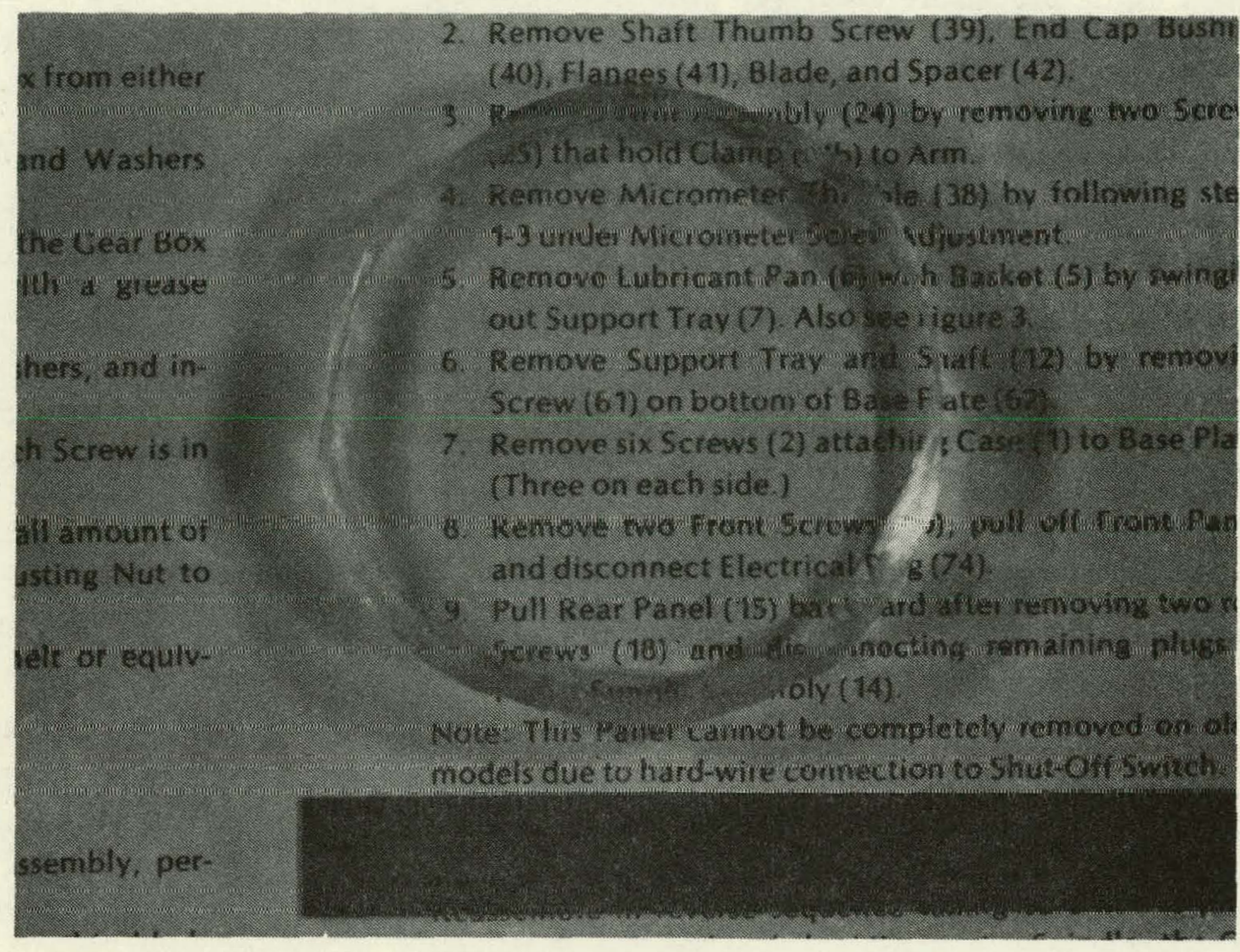

Figure 3. Photograph of a LiF crystal of $\langle 100\rangle$ orientation polished after forging to $70 \%$ reduction in height. 


\subsection{SINGLE-STEP FORGINGS}

Using the forging procedure described above, several $\mathrm{LiF}$ crystals of $\langle 100\rangle$ orientation were forged over a temperature range $300-600^{\circ} \mathrm{C}$ to deformations of up to 80 percent. Deformation is defined as the percentage reduction of the original height of the starting material. These forged samples were polished and examined visually, and using an optical microscope in transmission, for the presence of internal defects that might have been produced by press forging. These examinations indicated that excessive deformation at any temperature introduces veils, or internal cloudiness. The defects responsible for veils act as scattering centers and look like voids or partially healed cracks in an optical miscroscope. The observed limit for deformation without veiling was about 40 percent at $300^{\circ} \mathrm{C}$, increasing with increasing forging temperature to about $6 \mathrm{~b}$ percent at $600^{\circ} \mathrm{C}$ (see Figure 4).

A few crystals of $\langle 110\rangle$ and $\langle 111\rangle$ initial orientations were forged to determine the effects of initial orientation on veiling in press-forged LiF. After these samples were forged to 50 percent deformation at $500^{\circ} \mathrm{C}$, veils were observed in the billet of $\langle 111\rangle$ orientation, but not in that of $\langle 110\rangle$ orientation. A sample of $\langle 110\rangle$ orientation forged at $600^{\circ} \mathrm{C}$ to 69 percent deformation and two samples of $\langle 111\rangle$ orientation forged at $600^{\circ} \mathrm{C}$ to 60 percent deformation were observed to be nearly free of veils.

Press-forged LiF samples of $\langle 100\rangle$ and $<111>$ orientations were fairly circular in cross-sections, as shown in Figure 3 and Figure 5 respectively, whereas all press-forged $\mathrm{LiF}$ samples of $\langle 110\rangle$ orientations were elliptical in cross-section with the length of the minor diagonal equal to the diameter of the forging billet (see Figure 6). The major diagonal was found to lie along the trace of (110) plane in the forging billet. Note that the cloudiness seen in the photographs of as-forged crystals (Figures 5 and 6) is a surface effect and can be removed easily by polishing.

Several press-forged LiF crystals were examined metallographically. Microstructures of crystals forged to low reductions at $300^{\circ} \mathrm{C}$ consisted of low-angle grain boundaries and/or slip bands (areas of high dislocation density) separated by regions of fairly uniform dislocation density. An example of the latter is shown in Figure 7, which is a micrograph of a sample forged at $300^{\circ} \mathrm{C}$ to 30 percent reduction.

Microstructure of crystals forged at a temperature of $400^{\circ} \mathrm{C}$ or higher consisted of low and high angle grain boundaries. The formation of high angle grain boundaries was favored under the conditions of high deformations and high forging temperatures. Low 


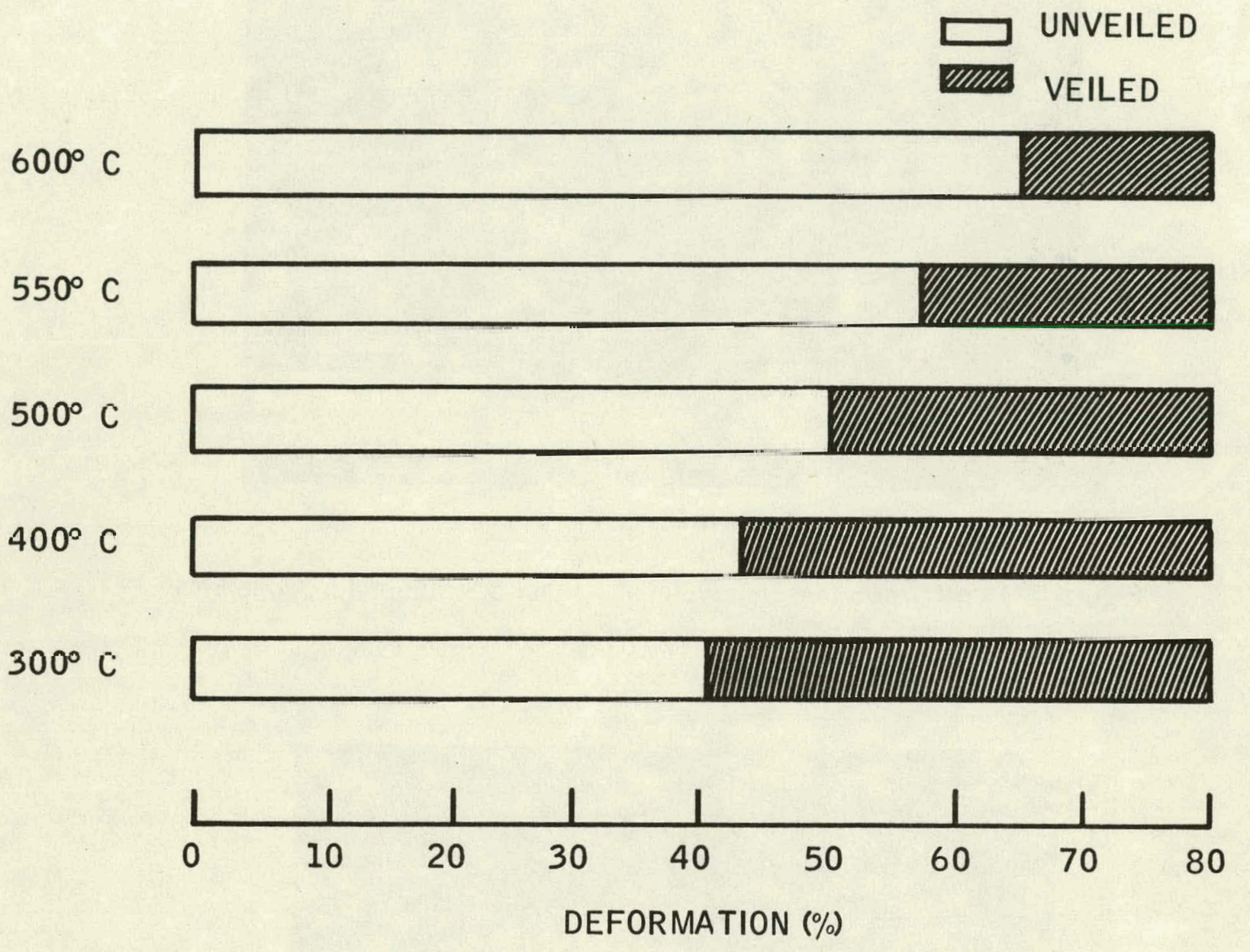

Figure 4. Excessive deformation at any temperature introduces internal cloudiness (veils) in LiF. This figure shows the approximate deformation limits at various temperatures. 


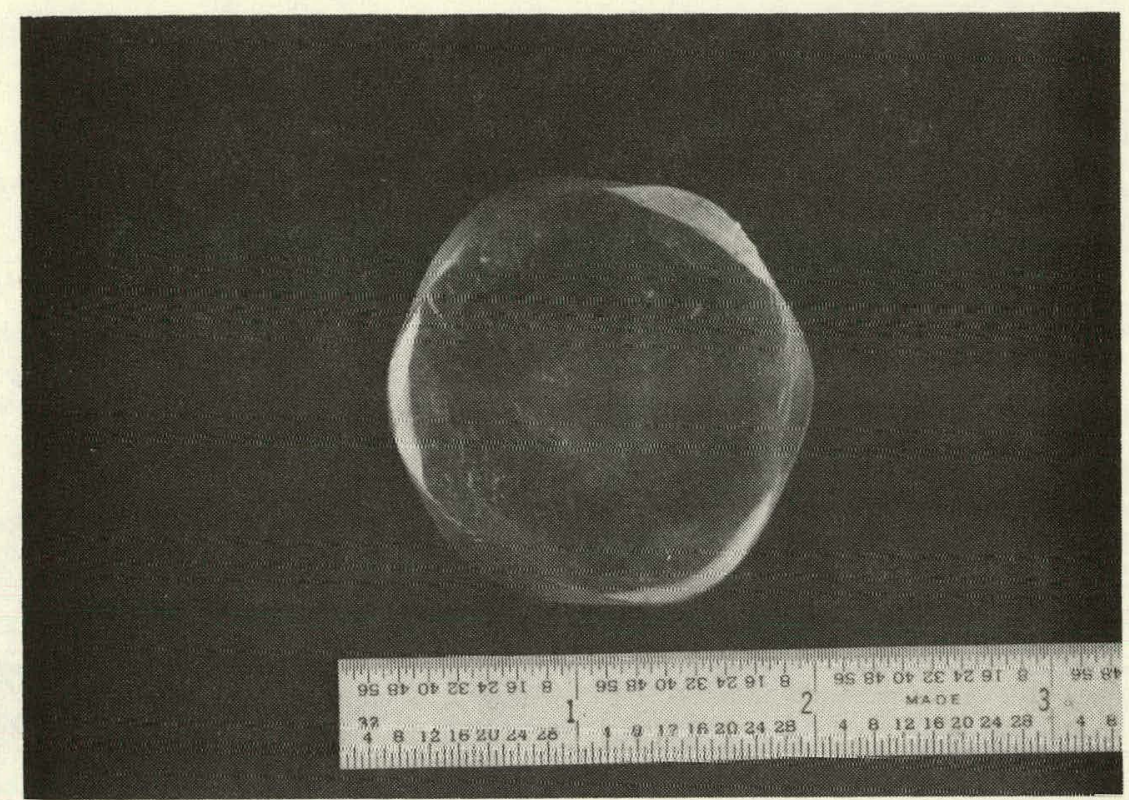

Figure 5. Photograph of a LiF crystal of $\langle 111\rangle$ orientation forged to $50 \%$ reduction in height.

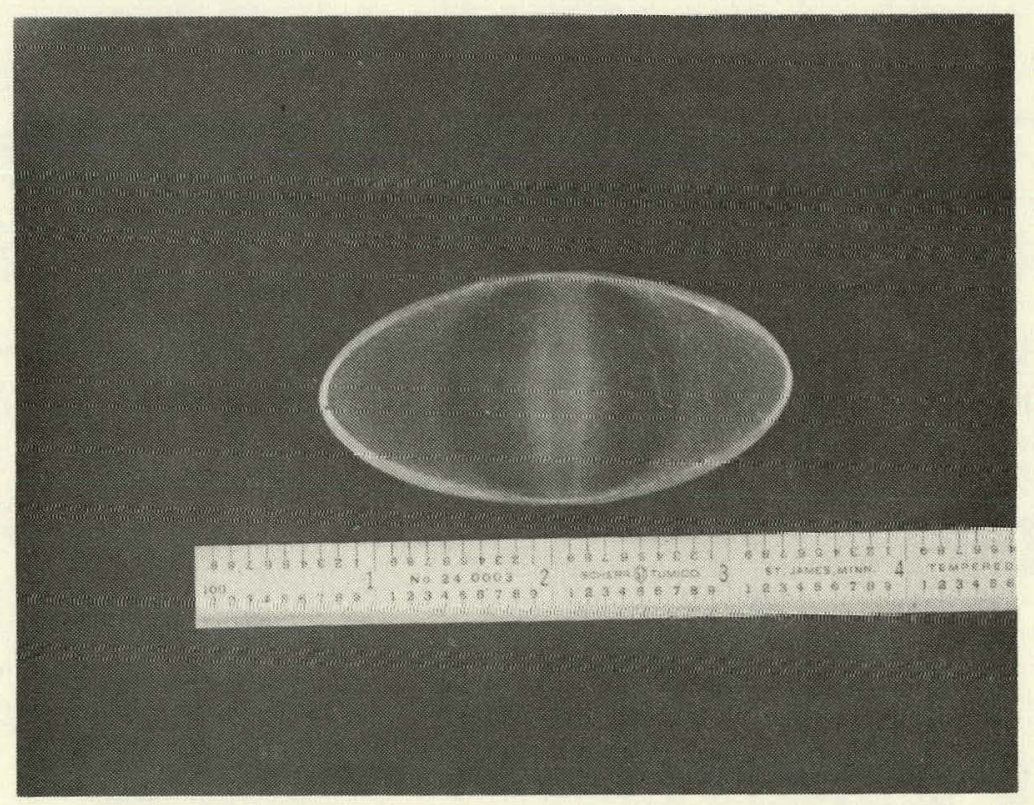

Figure 6. Photograph of a LiF crystal of $\langle 110\rangle$ orientation forged to $50 \%$ reduction in height. 
angle grain boundaries observed in a crystal forged at $400^{\circ} \mathrm{C}$ to 54 percent reduction in height are shown in Figure 8. The LiF crystals which were forged at $400^{\circ} \mathrm{C}$ to more than 65 percent reduction in height have yielded the lowest grain size $(10-15 \mu \mathrm{m})$ observed during the course of this program. In some LiF crystals which were forged at $400^{\circ} \mathrm{C}$ or $500^{\circ} \mathrm{C}$, a bimodal grain size was observed (see Figure 9).

Figure 4 indicates that the degree of deformation that can be imparted to an LiF single crystal without introducing veiling can be increased by increasing the forging temperature to above $600^{\circ} \mathrm{C}$. Metallographic observations, however, indicate that the employment of a forging temperature of $600^{\circ} \mathrm{C}$ or higher would be undesirable. In two out of three $\mathrm{LiF}$ crystals which were forged at $600^{\circ} \mathrm{C}$ to $\sim 65$ percent reduction, several large grains, formed apparently by secondary recrystallization either during forging or during subsequent cooling to room temperature, were observed (see Figure 10).

\subsection{TWO-STEP FORGINGS}

In order to improve the grain size uniformity and to suppress veiling, several LiF crystals of $\langle 100\rangle$ orientations were forged in two steps. In a two-step forging process, a crystal is given $\mathrm{X}$ percent deformation at some temperature $\mathrm{T}_{1}$ (step 1) and additional $\mathrm{Y}$ percent deformation at some temperature $\mathrm{T}_{2}$ (step 2). Between steps, the crystal is annealed at some temperature $T$ greater than $T_{1}$ and $T_{2}$ to induce recovery. The billets for various two-step forgings were right cylinders $(3.2 \mathrm{~cm}$ in diameter and $1.3-3.3 \mathrm{~cm}$ in height) or quarters obtained by cutting Harshaw crystals of $\langle 100\rangle$ orientation along the (010) and (001) planes.

All two-step forgings were examined visually for the presence of veils and were classified as veiled or unveiled. The results of this examination and the forging parameters of various two-step forgings are summarized in Table 2. The data in Table 2 indicate that the two-step forging approach permits a large scale deformation (amounting to 63-76 perent reduction in height) without introducing veils. Samples classified in Table 2 as unveiled may contain very few internal defects which are difficult to detect either visually or microscopically.

Some samples of two-step forgings were examined metallographically. The presence of fine and fairly uniform grains of size in the range $15-30 \mu \mathrm{m}$ was revealed in these examinations (see Figure 11). 


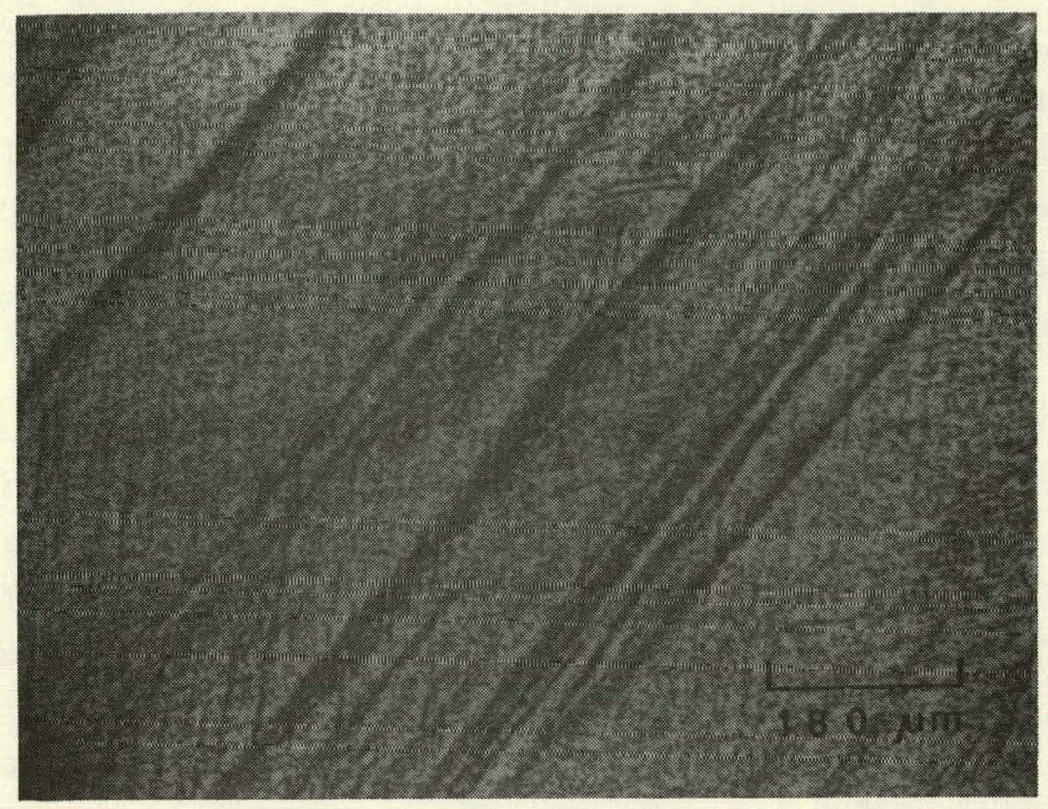

Figure 7. Microstructure of a LiF crystal forged at $300^{\circ} \mathrm{C}$ to $30 \%$ reduction in height.

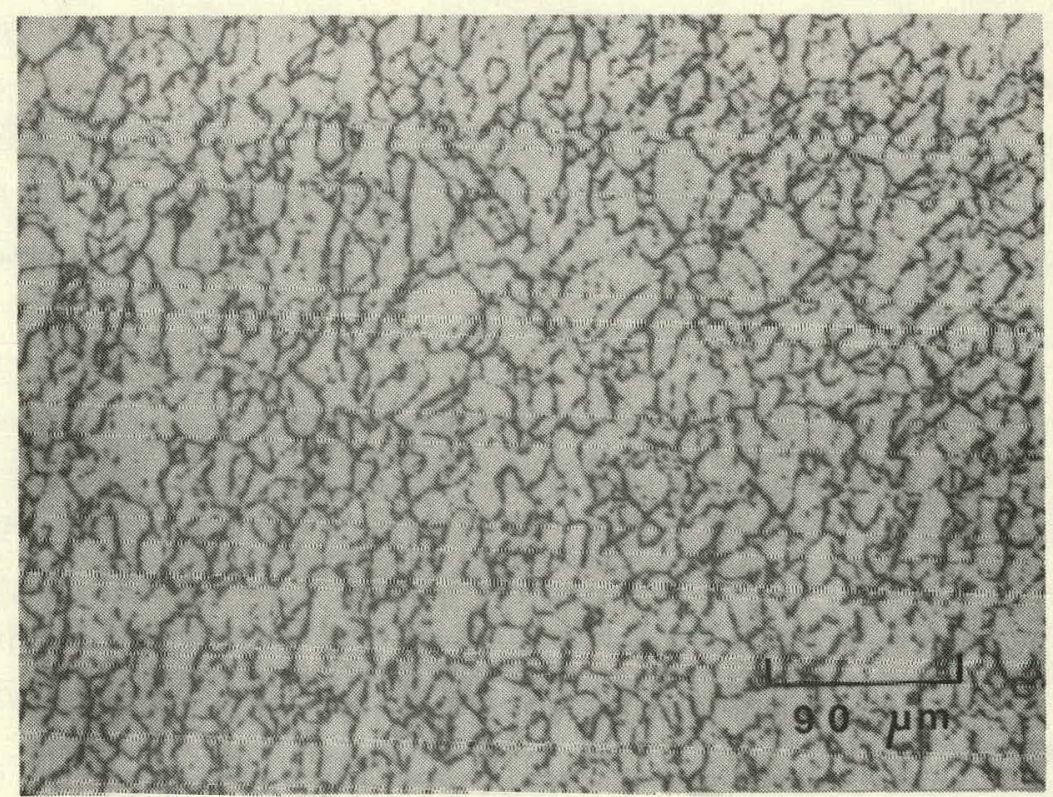

Figure 8. Low-angle grain boundaries in a LiF crystal forged at $400^{\circ} \mathrm{C}$ to $54 \%$ reduction in height. 


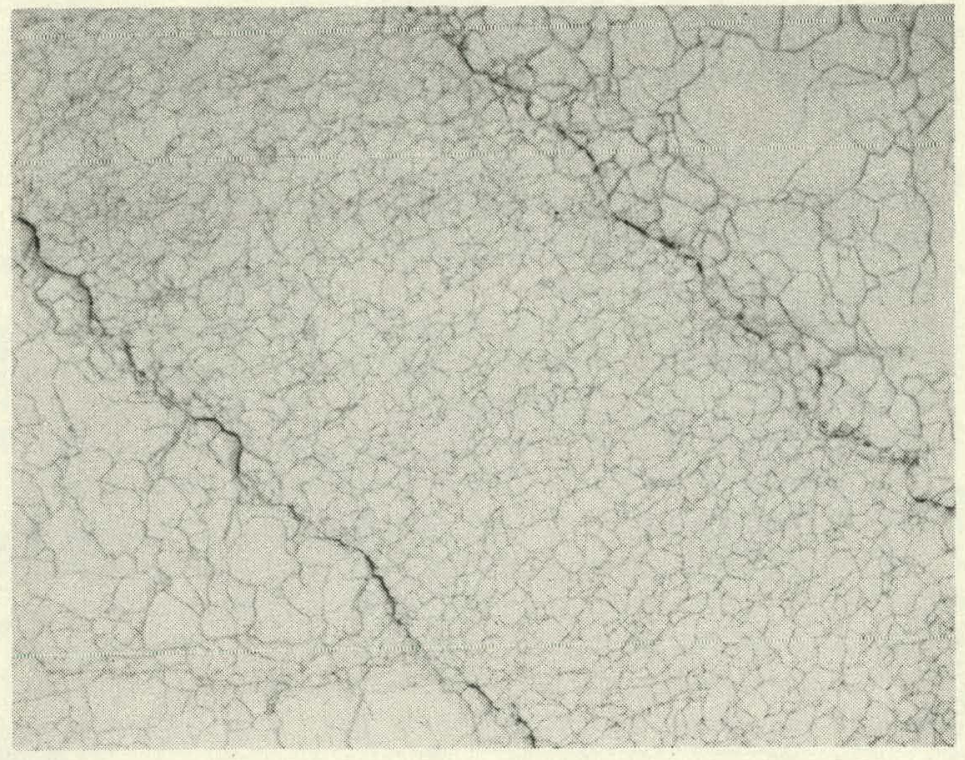

Figure 9. Microstructure of a LiF crystal forged at $500^{\circ} \mathrm{C}$ to $50 \%$ reduction in height (110X).

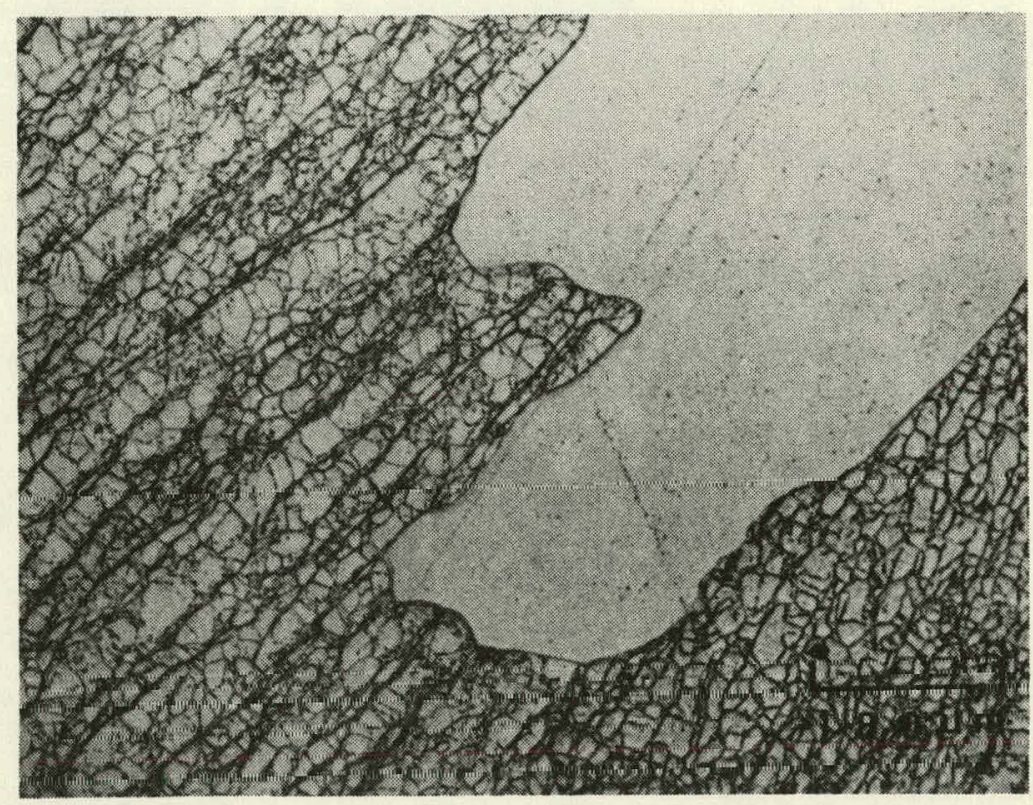

Figure 10. Microstructure of a LiF crystal forged at $600^{\circ} \mathrm{C}$ to $63 \%$ reduction in height. 
Table 2. Forging Parameters for Various Two-Step Forgings. *

\begin{tabular}{|c|c|c|c|c|c|c|c|c|c|}
\hline \multirow[b]{2}{*}{ Designation } & \multirow[b]{2}{*}{ Initial Jimeasions } & \multicolumn{3}{|c|}{ Step 1} & \multicolumn{3}{|c|}{ Ste: 2} & \multirow{2}{*}{$\begin{array}{c}\text { Overall } \\
\text { Reduction } \\
\text { (ii) }\end{array}$} & \multirow[b]{2}{*}{ Comments } \\
\hline & & \begin{tabular}{|c|}
$\begin{array}{c}\text { Reduction } \\
(\%)\end{array}$ \\
\end{tabular} & Forging & $\begin{array}{l}\text { Temperature } \\
\left({ }^{\circ} \mathrm{C}\right)\end{array}$ & $\begin{array}{c}\text { Rəduction } \\
\left({ }^{\circ} \mathrm{C}\right) \\
\end{array}$ & Forgirg & $\begin{array}{l}\text { Temperature } \\
\left({ }^{\circ} \mathrm{C}\right)\end{array}$ & & \\
\hline $\mathrm{H}-27(\mathrm{~S}-2)$ & $\begin{array}{l}3.2 \mathrm{~cm} \mathrm{diameter} \mathrm{x} \\
1.3 \mathrm{~cm} \text { height }\end{array}$ & 47 & & 500 & 47 & & 500 & 70 & Unveiled \\
\hline $\mathrm{H}-28\left(\mathrm{q}^{*}-1\right)$ & $2.5 \mathrm{~cm}$ height & 55 & & 600 & 45 & & 500 & 76 & Veiled \\
\hline$H-28(q-2)$ & $2.5 \mathrm{~cm}$ height & 43 & & 400 & 56 & & 500 & 75 & Unveiled \\
\hline $\mathrm{H}-30$ & $\begin{array}{l}3.2 \mathrm{~cm} \text { diameter } \mathrm{x} \\
1.8 \mathrm{~cm} \text { height }\end{array}$ & 35 & & 350 & 50 & & 550 & 63 & Unveiled \\
\hline $\mathrm{H}-32$ & $\begin{array}{l}3.2 \mathrm{~cm} \text { diameter } \mathrm{x} \\
3.3 \mathrm{~cm} \text { reight }\end{array}$ & 42 & & 400 & 52 & & 525 & 73 & Veiled \\
\hline $\mathrm{H}-34(\mathrm{q}-1)$ & $2.5 \mathrm{~cm}$ teight & 28 & & 300 & 58 & & 500 & 69 & Unveiled \\
\hline $\mathrm{H}-34(\mathrm{q}-2)$ & $2.5 \mathrm{~cm}$ height & 28 & & 300 & 62 & & 525 & 72 & Unveiled \\
\hline $\mathrm{H}-34(q-3)$ & $2.5 \mathrm{~cm}$ height & 72 & & 525 & & & & 72 & $\begin{array}{l}\text { Veiled, One-Step } \\
\text { Forging }\end{array}$ \\
\hline $\mathrm{H}-38$ & $\begin{array}{l}32 \mathrm{~cm} \text { diameter } \mathrm{x} \\
1.9 \mathrm{~cm} \text { height }\end{array}$ & 35 & & 350 & 50 & & 500 & 69 & Unveiled \\
\hline $\mathrm{H}-41$ & $\begin{array}{l}3.2 \mathrm{~cm} \text { diameter } \mathrm{x} \\
1.8 \mathrm{~cm} \text { heigit }\end{array}$ & 50 & & 500 & 30 & & 400 & 66 & Veiled \\
\hline
\end{tabular}

* All two-step forgings were annealed at $700^{\circ} \mathrm{C}$ for $1-4$ hours between steps.

**q-quarter. 


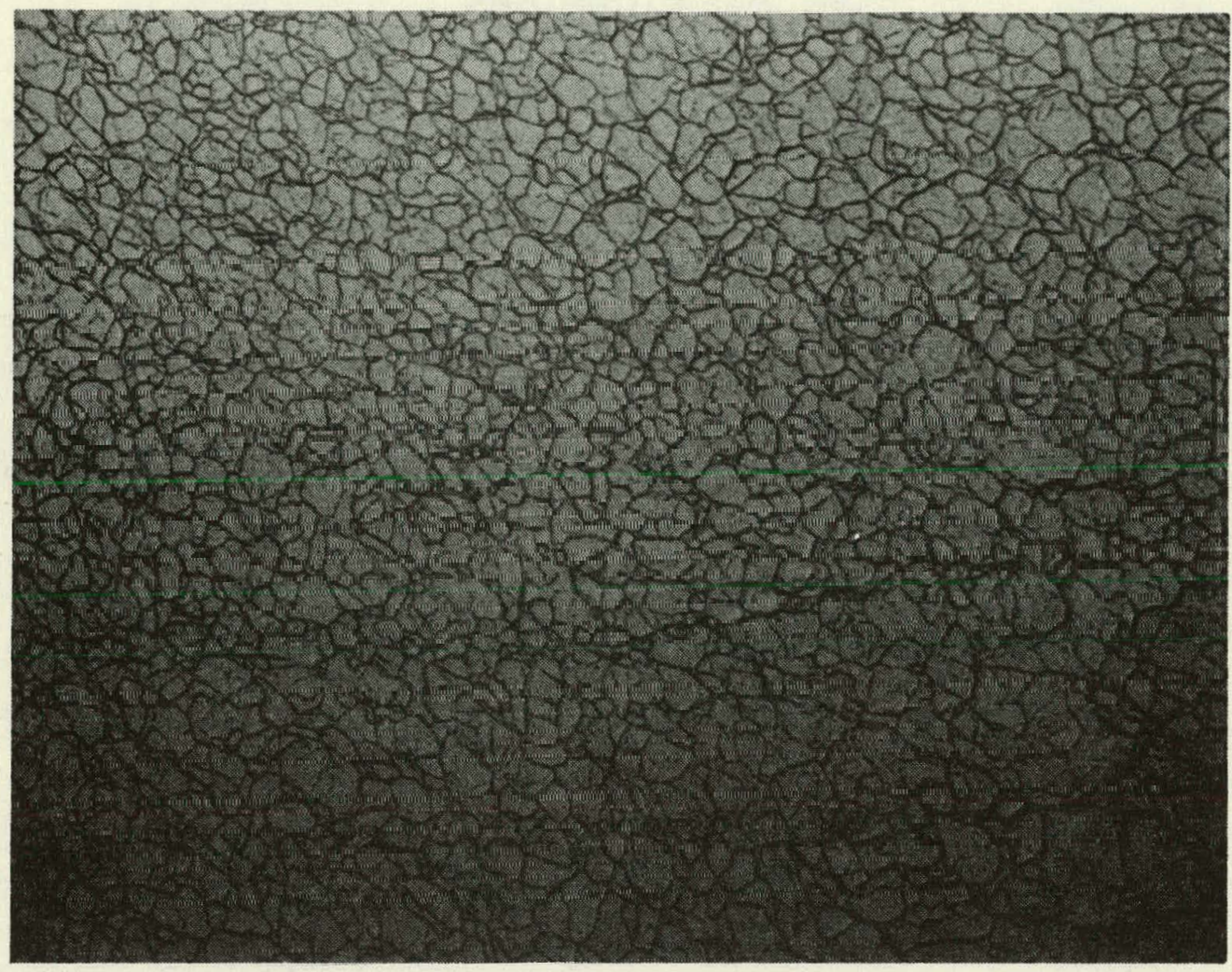

Figure 11. Microstructure of two-step forging $H-27(S-2)(120 X)$. 


\section{Section 3 \\ Optical Properties}

\subsection{OPTICAL INHOMOGENEITY}

Optical inhomogeneities of several LiF crystals were measured, both before and after forging, using the technique described by Bennett et al.8 The optical inhomogeneity is defined by $\Delta n / n$, where $\Delta n$ is the variation in the index of refraction $n$ of the sample averaged over its thickness. A sample with flat, parallel sides was placed between coated quartz plates to form a Fizeau interferometer using a $633 \mathrm{~nm} H e N e$ laser as a light source. An index matching fluid was used in the contact regions lu eliminate the cffect of the sample surfaces. The fringe pattern was detected with a TV camera, displayed on a TV monitor screen, and photographed with a Polaroid camera.

Analysis of the interferograms was performed by digitizing the fringes and then converting the digitized interferograms to contours of optical path difference through the use of the computer program FRINGE, developed at the Optical Science Center, University of Arizona. 9 The maximum span of the optical path difference across the sample was taken as a measure of inhomogeneity. Table 3 summarizes the measured optical inhomogeneities of various $\mathrm{LiF}$ samples, along with their forging parameters. The data indicate that the Harshaw $\mathrm{LiF}$ single crystals possess very good optical homogeneity $\left(\Delta \mathrm{n} / \mathrm{n}\right.$ in the range $\left.7 \times 10^{-7}-3 \times 10^{-6}\right)$, and that the LiF single crystals can be press forged without seriously degrading their optical homogeneities. In the worst case, sample $\mathrm{H}-\langle 110\rangle-2$, the observed increase in $\Delta \mathrm{n} / \mathrm{n}$ is by about a factor of eight. Out of the remaining six samplex, $\mathrm{H}-<111>-4, \mathrm{H}-28$ (q-2), $\mathrm{H}-32$ and $\mathrm{H}-36$ (q-4), the observed increase in $\Delta \mathrm{n} / \mathrm{n}$ is less than a factor of two. Samples forged in two or more steps are seen to have retained optical homogeneity in the range of a few parts per million.

\subsection{OPTICAL ABSORPTION}

Initially in this program, optical ahsorption measurements were made on several single-crystal and polycrystalline LiF samples in the region 200-650 nm using a Cary 14 spectrophometer. Because of the low sensitivity of this method, the effects of press forging operation on the residual ultraviolet and visible absorption could not be determined reliability. The measured absorption was nearly the same hefore and after forging; however, these measurements did reveal an increase in absorption with 
Table 3. Optical Inhomogeneity, Before and After Forging, of Various LiF Samples.

\begin{tabular}{|l|l|c|c|}
\hline & \multicolumn{1}{|c|}{$\begin{array}{c}\text { Forging Parameters } \\
\text { Sample }\end{array}$} & \multicolumn{2}{c|}{ Inhomogeneity $(\Delta \mathrm{n} / \mathrm{n})$} \\
\cline { 3 - 4 }$($ Percent Reduction - Forging Temperature) & Before Forging & After Forging \\
\hline $\mathrm{H}-<110>-2$ & $50 \%-500^{\circ} \mathrm{C}$ & $7.1 \times 10^{-7}$ & $5.4 \times 10^{-6}$ \\
$\mathrm{H}-<110>-3$ & $69 \%-600^{\circ} \mathrm{C}$ & $1.5 \times 10^{-6}$ & $8.1 \times 10^{-6}$ \\
$\mathrm{H}-<111>-4$ & $50 \%-500^{\circ} \mathrm{C}$ & $1.3 \times 10^{-6}$ & $1.7 \times 10^{-6}$ \\
$\mathrm{H}-28(\mathrm{q}-1)$ & $55 \%-600^{\circ} \mathrm{C}+45 \%-600^{\circ} \mathrm{C}$ & $1.7 \times 10^{-6}$ & $7.0 \times 10^{-6}$ \\
$\mathrm{H}-28(\mathrm{q}-2)$ & $43 \%-400^{\circ} \mathrm{C}+56 \%-500^{\circ} \mathrm{C}$ & $1.7 \times 10^{-6}$ & $2.6 \times 10^{-6}$ \\
$\mathrm{H}-32$ & $42 \%-400^{\circ} \mathrm{C}+52 \%-525^{\circ} \mathrm{C}$ & $2.1 \times 10^{-6}$ & $2.3 \times 10^{-6}$ \\
$\mathrm{H}-36(\mathrm{q}-4)$ & $37 \%-350^{\circ} \mathrm{C}+30 \%-360^{\circ} \mathrm{C}+50 \%-500^{\circ} \mathrm{C}$ & $3.0 \times 10^{-6}$ & $5.5 \times 10^{-6}$ \\
\hline
\end{tabular}

decreasing wavelength in the ultraviolet for all $\mathrm{LiF}$ starting materials, the observed increase being much greater for Optovac and University of Utah LiF than Harshaw LiF. In addition, the presence of several absorption bands in the region $200-400 \mathrm{~nm}$ in the University of Utah $\mathrm{LiF}$ were revealed. Figure 12 illustrates the absorption spectra of various $\mathrm{LiF}$ samples.

In order to determine the influence of forging parameters on the residual ultraviolet and visible absorptions in $\mathrm{LiF}$, absorption measurements were made calorimetrically on several Harshaw LiF samples, both before and after forging, using a line-tunable argon ion laser. The laser was a Spectra-Physics Model 171-19 which operated single line at nine wavelengths in the visible $(454.5-528 \mathrm{~nm})$ at power levels in the range 0.7-6.5 watts, and multiline in the ultraviolet at a power level of 2 watts which was distributed 45 percent, 45 percent, and 10 percent among three lines of wavelengths $364 \mathrm{~nm}, 351 \mathrm{~nm}$, and $339 \mathrm{~nm}$, respectively. Most absorption measurements were made at three wavelengths in the visible, $514.5 \mathrm{~nm}, 488 \mathrm{~nm}$, and $457.9 \mathrm{~nm}$, and using multiline operation in the ultraviolet.

The absorption data obtained using multiline beam are subject to much greater variations than those obtained using a single-line beam because the relative intensities of the three lines in a multiline ultraviolet beam of an argon ion laser varies significantly with operating conditions. This strongly affects the measured absorption in the case of a material like $\mathrm{LiF}$ in which the absorption increases with decreasing wavelength in the ultraviolet. For this reason, single-line ultraviolet absorption data were obtained from some LiF samples using an external prism. 


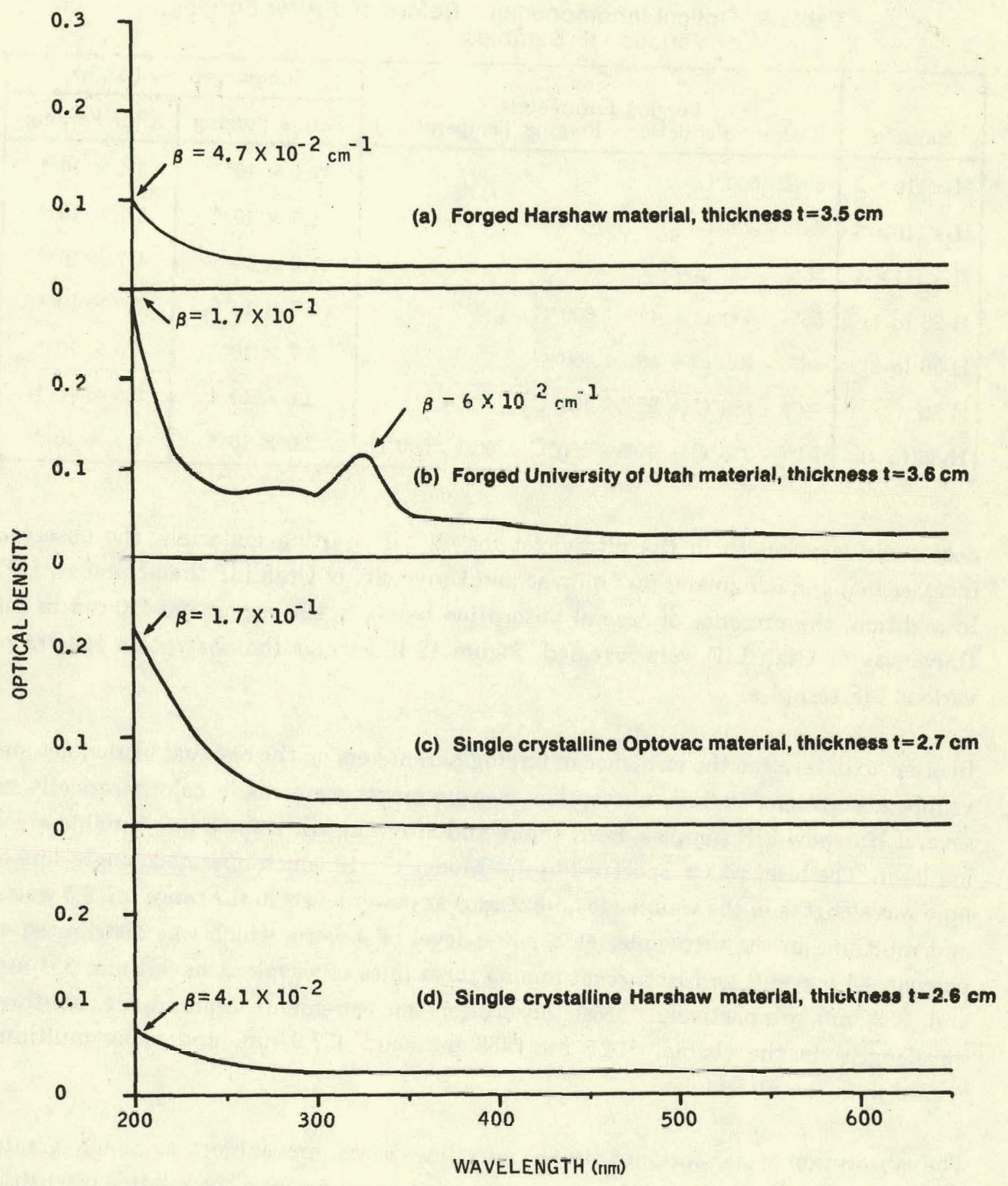

Figure 12. Optical absorption spectra of various LiF samples (values of absorption coefficient $\beta$ in $\mathrm{cm}^{-1}$ are indicated). 
Table 4 summarizes the laser calorimetric data in the visible and ultraviolet obtained during the course of this program. Some of these data are also shown in Figure 13. The data in Table 4 indicate that the press forging increases the residual ultraviolet and visible absorption in $\mathrm{LiF}$, but that the observed increase is nominal (less than a factor of two) in at least four out of six samples.

Calorimetric measurements in the infrared $(1.06,1.3,2.7$, and $3.8 \mu \mathrm{m})$ also showed a nominal change in absorption as a result of press forging (see Table 5).

\subsection{STRESS BIREFRINGENCE}

Stress birefringence measurements were made on a few samples of single-crystal and press-forged $\mathrm{LiF}$ using a circular polariscope which provides a quantitative measure of stress birefringence derivable from the measured angle of rotation of a final polarizer.10 Measurements made at several points on samples of single-crystal and press-forged LiF indicated a residual stress birefringence of less than $10 \mathrm{~nm} / \mathrm{cm}$ for both materials.

\subsection{SCATTERING PROFILES}

Scattering profiles of several single-crystal and press-forged $\mathrm{LiF}$ were obtained with a laser flying spot scanner, which used a helium-neon laser as a light source, galvanometer deflectors, and a photodiode positioned such that it detected scattered light at $90^{\circ}$ from the forward direction. A scattering profile of a veiled, press-forged LiF sample obtained by scanning over a $5 \mathrm{~mm} \times 5 \mathrm{~mm}$ area is shown in Figure 14 .

The scattering profile defines areas of high scattering due to the presence of internal defects; thus, it is a sensitive method of detecting veils. The results may be quantified by processing the data to determine the signal size distribution. An example is shown in Figure 15, which is the distribution relevant to the profile of Figure 14. The number of spots in the two-dimensional scan, which showed a given signal amplitude, are plotted versus signal amplitude. The large peak near $0.4 \mathrm{~V}$ is the background from unveiled areas. The tail extending to $0.8 \mathrm{~V}$ is the contribution due to the small areas with high scattering.

Scattering profiles of some two-step forgings which appeared unveiled in a visual examination indicated the presence of a few scattering centers which were not seen in the scattering profiles of single crystals forged to low reductions. Such scattering centers were fine and their density low, suggesting that a fine adjustment of the two-step forging 
Table 4. Summary of Ar-ion Laser Calorimetric Data on Single-Crystal and Press-Forged LiF.

\begin{tabular}{|c|c|c|c|c|c|c|c|c|}
\hline & & \multicolumn{7}{|c|}{ Absorption Coefticient, $\left(\mathrm{cm}^{-1}\right) \times 10^{-3}$} \\
\hline \multirow{2}{*}{\multicolumn{2}{|c|}{ Sample }} & \multirow[b]{2}{*}{$514.5 \mathrm{~nm}$} & \multirow[b]{2}{*}{$188 \mathrm{~nm}$} & \multirow[b]{2}{*}{$457.9 \mathrm{~nm}$} & \multirow{2}{*}{$\begin{array}{l}\text { Multi-line } \\
\text { Ultraviolet }\end{array}$} & \multicolumn{3}{|c|}{ Single-line Ultraviolet } \\
\hline & & & & & & $364 \mathrm{~nm}$ & $351 \mathrm{~nm}$ & $339 \mathrm{~nm}$ \\
\hline \multirow[b]{2}{*}{$11-30$} & $\begin{array}{l}\text { Single } \\
\text { Crysta } 1\end{array}$ & 1.0 & 1.1 & 1.2 & 2.4 & & & \\
\hline & $\begin{array}{l}\text { Forbod } \\
350 \%-30^{\prime} \\
550 c-5 n^{\circ} \\
\end{array}$ & 1.7 & 2.0 & 2.3 & 3.9 & & & \\
\hline \multirow{3}{*}{$11-11$} & $\begin{array}{l}\text { Single } \\
\text { Crystial }\end{array}$ & 1.5 & 1.7 & 2.5 & 7.2 & & & \\
\hline & Forred & & & & & & & \\
\hline & $525 \mathrm{c}-61 \%$ & 2.2 & 2.3 & 2.3 & 18 & 12 & 14 & 45 \\
\hline \multirow[b]{2}{*}{$11-38$} & $\begin{array}{l}\text { Single } \\
\text { Crystal }\end{array}$ & 1.1 & 1.1 & 1.3 & 2.1 & & & \\
\hline & $\begin{array}{l}\text { Forked } \\
350 c-50 \% \\
500 c-50 \% \\
\end{array}$ & 1.8 & 2.0 & 2.6 & 4.4 & & & \\
\hline \multirow[b]{2}{*}{$11-.11$} & $\begin{array}{l}\text { Single } \\
\text { Crystal } \\
\end{array}$ & & & & 2.7 & 1.5 & 1.9 & \\
\hline & $\begin{array}{c}\text { Forged } \\
500 c-50 \% \\
400 c-15 \%\end{array}$ & 5.5 & 5.7 & 6.5 & 8.6 & & & \\
\hline \multirow[b]{2}{*}{$11-12$} & $\begin{array}{l}\text { Single } \\
\text { Crystal }\end{array}$ & 0.71 & 0.64 & 0.80 & 5.4 & & & \\
\hline & $\begin{array}{c}\text { Forged } \\
400 \mathrm{C}-61 \%\end{array}$ & 2.7 & 2.7 & 3.0 & 4.6 & & & \\
\hline \multirow{3}{*}{$11--110=-4$} & $\begin{array}{l}\text { Single } \\
\text { Lrystul }\end{array}$ & 0.30 & ก $3 n$ & ก 3 A & 0.43 & $0 . y^{\prime}$ & 0.96 & 1.41 \\
\hline & Forged & & & & & & & \\
\hline & $500 c-50^{\prime \prime} c$ & 0.65 & 0.69 & 0.72 & 2.1 & 1.35 & 1.77 & $2 \mathrm{RB}$ \\
\hline
\end{tabular}




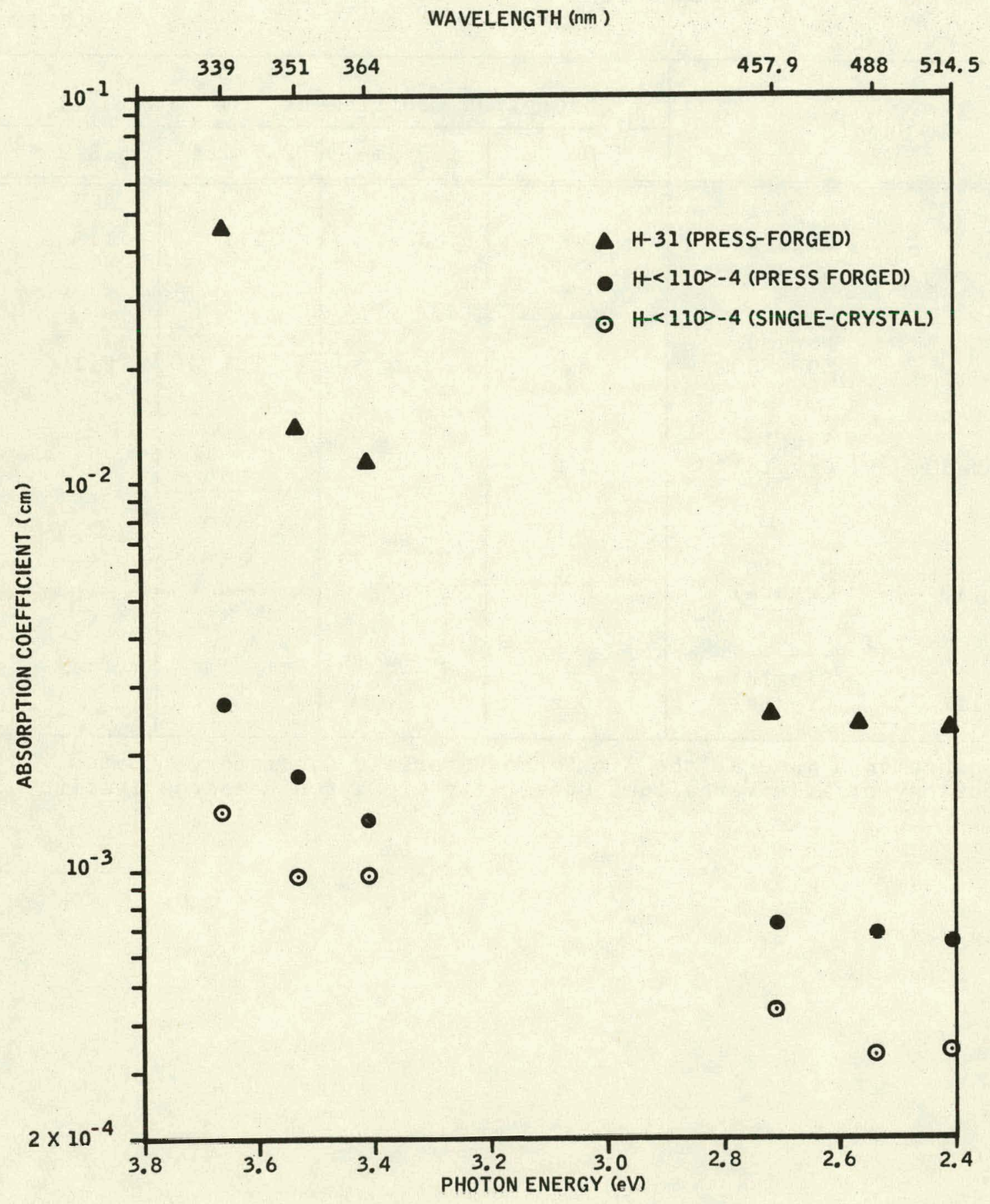

Figure 13. Residual ultraviolet and visible absorption in LiF. 
Table 5. Laser Calorimetric Data at $1.06 \mu \mathrm{m}, 1.3 \mu \mathrm{m}, 2.7 \mu \mathrm{m}$, and $3.8 \mu \mathrm{m}$ on LiF.

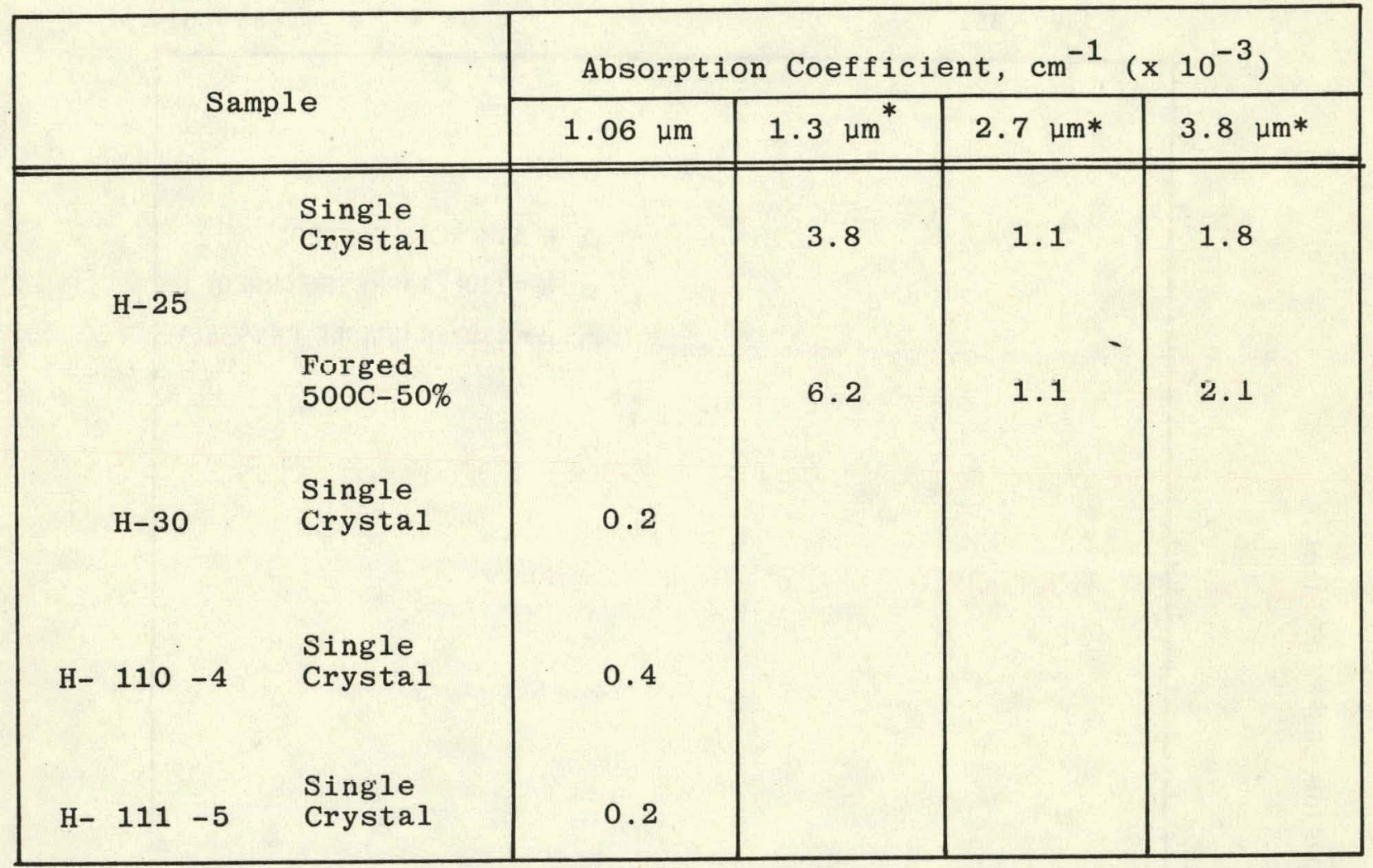

* Measurements made at the Air Force Materials Laboratory, Dayton, Ohio. Courlesy of Nilo Fornalius, Inniversity of Dayton Research Institute. 


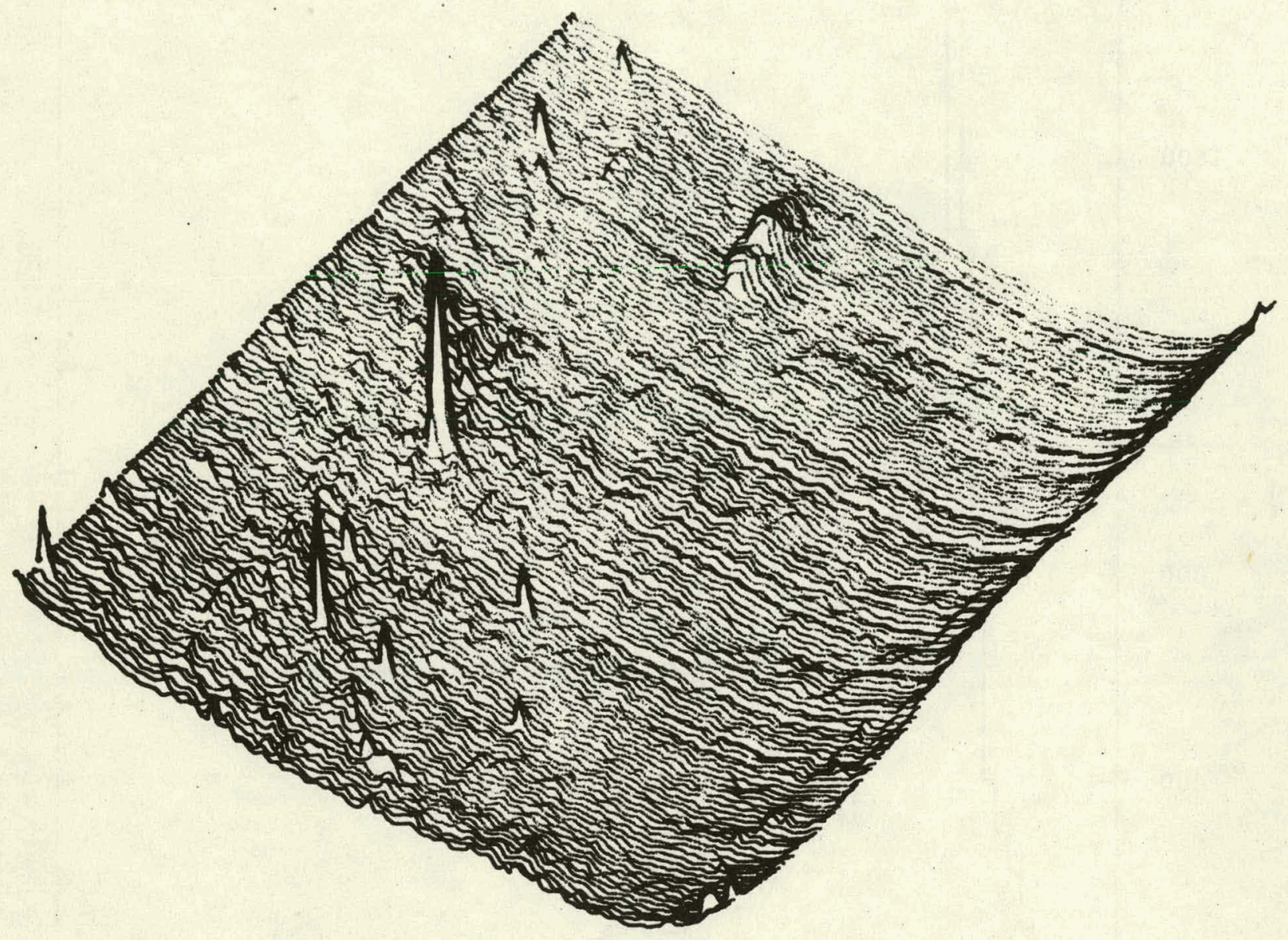

Figure 14. Scattering profile of a $5 \mathrm{~mm} \times 5 \mathrm{~mm}$ area of a veiled sample of press-forged LiF. 


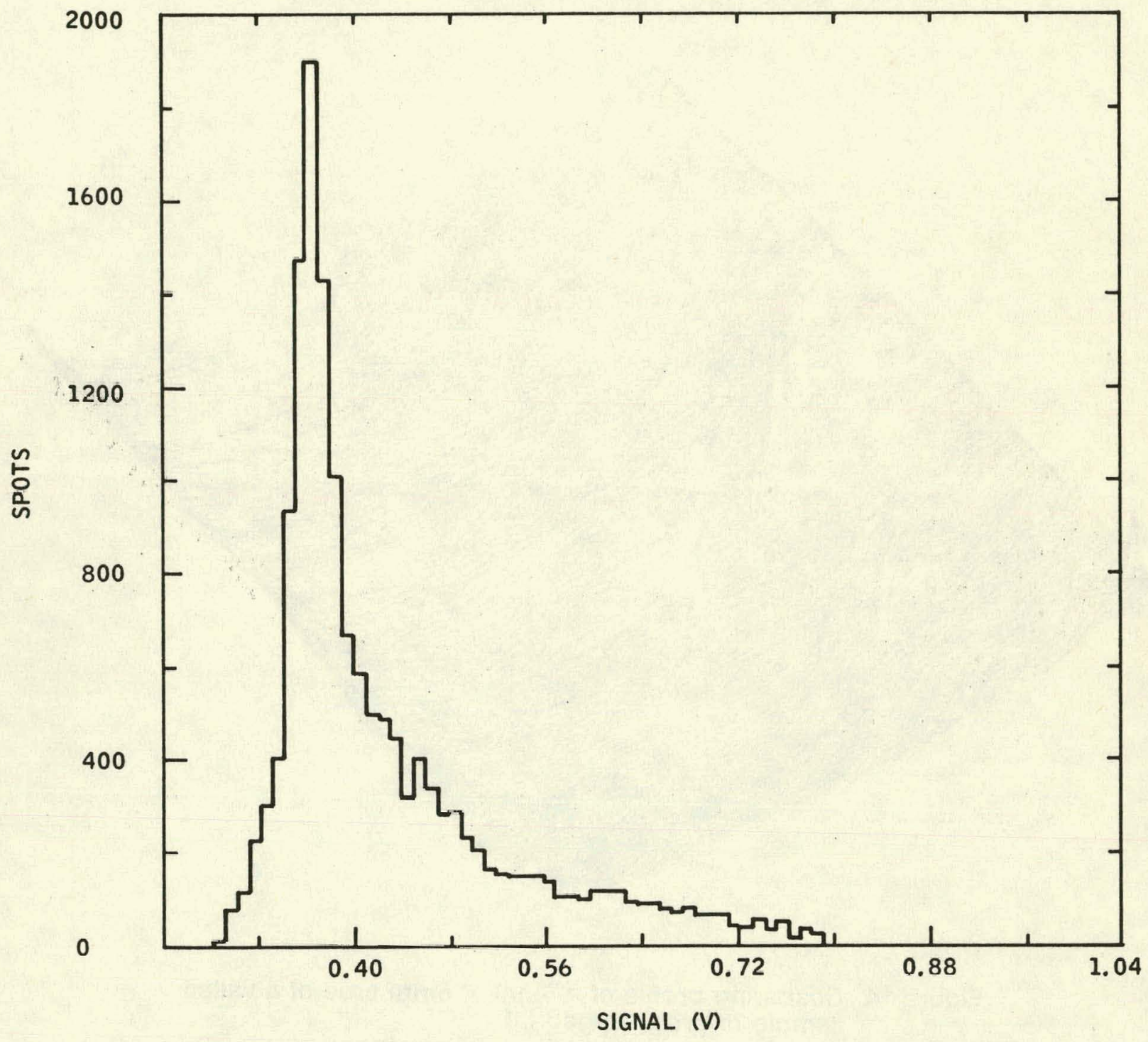

Figure 15. Distribution of scattering signal amplitudes for a veiled sample of press-forged LiF. 
parameters would be required before veils could be completely eliminated from $\mathrm{LiF}$ crystals press-forged to a total reduction of $\sim 75$ percent.

\subsection{DAMAGE THRESHOLDS}

Damage thresholds of both single-crystal and press-forged LiF were measured at the Lawrence Livermore Laboratory. Dr. D. Milam measured the damage thresholds for 1-ns, 1064-nm laser pulses. The samples used in his study were forged at Honeywell and polished at either Lawrence Livermore Laboratory or at the Honeywell Ceramics Center. Table 6 summarizes the data obtained by Dr. Milam. Within the limits of the experimental errors, the near surface damage threshold is not significantly changed by the forging process. Also, the polishing procedure used does not seem to change the surface threshold significantly. The bulk damage thresholds remain high after forging; in fact, higher than the values for the single crystals. The bulk damage threshold for one single-crystal sample seems anomalously low.

Drs. T.F. Deaton and W.L. Smith measured the damage thresholds for 700-ps, 266-nm laser pulses.11 Their data are presented in Table 7. Both single-crystal and press-forged LiF samples used in their study were polished at Honeywell. Under these irradiation conditions, the relatively high value of damage threshold does not appear to be reduced by the forging operation.

Table 6. Damage Thresholds for 1-ns, $1064 \mathrm{~nm}$ Laser Pulses for Single-Crystal and Press-Forged LiF.

\begin{tabular}{|l|l|c|}
\hline \multicolumn{1}{|c|}{ Sample } & \multicolumn{1}{|c|}{ Polish } & Damage Threshold $\left(\mathrm{J} / \mathrm{cm}^{2}\right)$ \\
\hline \hline & & Rear Surface \\
\hline $\begin{array}{l}\text { Single Crystal } \\
\text { Press Forged } \\
\text { Single Crystal } \\
\text { Press Forged }\end{array}$ & $\begin{array}{l}\text { Lawrence Livermore Laboratory } \\
\text { Lawrence Livermore Laboratory } \\
\text { Honeywel1 }\end{array}$ & $\begin{array}{c}10 \pm 10 \\
\mathbf{8} \pm 1.5\end{array}$ \\
\hline
\end{tabular}

*Courtesy of Dr. D. Milam, Lawrence Livermore Laboratory 
Table 7. Damage Thresholds for 700-ps, 266-nm Laser Pulses for Single-Crystal and Press-Forged LiF.

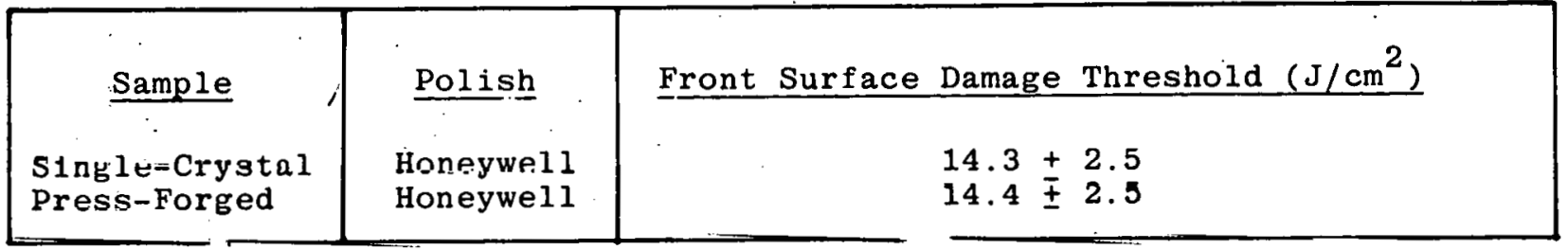

*Courtesy of Drs. T.F. Deaton and W. L. Smith, Lawrence Livermore Laboratory 


\section{Section 4 \\ Mechanical Properties}

The following mechanical properties of $\mathrm{LiF}$ were studied in the program: yield strength in compression, proportional limit (defined as the stress value at which the load-time curve recorded on a strip chart appears to deviate from linearity), fracture strength in 3 or 4-point bending, fracture energy, and microyield behavior.

\subsection{YIELD STRENGTHS}

Specimens for compression tests were of approximate dimensions $4 \mathrm{~mm} \times 4 \mathrm{~mm} \times$ $10 \mathrm{~mm}$. These were prepared by cutting along $\{100\}$ planes in the case of single crystals. Specimens of forged $\mathrm{LiF}$ were polished in fluoboric acid and those of single-crystal $\mathrm{LiF}$ were annealed in a helium atmosphere at $700^{\circ} \mathrm{C}$ for 2 hours before testing to remove any residual stresses that might have been introduced by cutting and polishing operations.

Some of the early experiments in this program involved the simultaneous forging of four crystals of different initial heights to the same final height, yielding crystals with four different reductions in one forging run. The forging blanks for these experiments, which were conducted at $300^{\circ} \mathrm{C}, 400^{\circ} \mathrm{C}$ and $550^{\circ} \mathrm{C}$ were obtained by cutting Harshaw crystals along $\{100\}$ planes passing through their axes. The resulting quarters were subsequently cut to obtain forging blanks of the required initial heights. Specimens were taken from each of these forgings and their yield strengths in compression were determined at a crosshead speed of $0.025 \mathrm{~cm} / \mathrm{min}$. The data obtained are summarized in Table 8 , where a variation in yield strength from about 13 to $54 \mathrm{MN} / \mathrm{m}^{2}$ with forging temperature and percent reduction is seen. Measured yields stresses of single-crystal and other press-forged LiF are shown in Table 9. Data on single crystulline materlal from Ahlquist 12 are included.

\subsection{PROPORTIONAL LIMIT AND FRACTURE STRENGTH}

Proportional limits and fracture strengths of single-crystal and press-forged LiF were determined by 3-point and 4-point bend tests. The results of 4-point bend tests are discussed in Section 4.4. The 3-point bend tests were conducted on specimens of approximate dimensions $2.5 \mathrm{~mm} \times 5 \mathrm{~mm} \times 25 \mathrm{~mm}$ over a span of $18 \mathrm{~mm}$ at a crosshead speed of $0.25 \mathrm{~cm} / \mathrm{min}$ in an Instron testing machine. The results of these tests are presented in Table 9. 
Table 8. Yield Strengths in Compression of Press-Forged LiF.

\begin{tabular}{|l|c|c|c|}
\hline $\begin{array}{l}\text { Forging } \\
\text { Number }\end{array}$ & $\begin{array}{c}\text { Forging } \\
\text { Temperature } \\
\text { (OC) }\end{array}$ & $\begin{array}{c}\text { Percent } \\
\text { Reduction }\end{array}$ & $\begin{array}{c}\text { Yield Stress* } \\
\left(\mathrm{MN} / \mathrm{m}^{2}\right)\end{array}$ \\
\hline \hline H8 & 300 & 15 & $33.3 \pm 1.7$ \\
H9 & 300 & 26 & $39.1 \pm 4.3$ \\
H10 & 300 & 34 & $54.5 \pm 11.3$ \\
H11 & 300 & 43 & $42.5 \pm 3.0$ \\
H12 & 400 & 20 & $13.1 \pm 1.06$ \\
H13 & 400 & 30 & $20.5 \pm 1.05$ \\
H14 & 400 & 38 & $26.0 \pm 3.3$ \\
H15 & 400 & 46 & $23.9 \pm 4.4$ \\
H16 & 550 & 60 & $.31 .11 \pm 3.8$ \\
H17 & 550 & 67 & $37.2 \pm 7.8$ \\
H18 & 550 & 71 & $39.0 \pm 7.8$ \\
H19 & 530 & 73 & $38.0 \pm 3.4$ \\
\hline
\end{tabular}

*0.1\% offset.

Table.9. Mechanical Properties of LiF.

\begin{tabular}{|c|c|c|c|c|}
\hline \multirow[b]{2}{*}{ Sample } & \multirow[b]{2}{*}{$\begin{array}{c}\text { Yield Stress } \\
\left(\mathrm{MN} / \mathrm{m}^{2}\right)^{*}\end{array}$} & \multicolumn{2}{|c|}{ property } & \multirow[b]{2}{*}{$\begin{array}{c}\text { Fracture Energy } \\
\left(\mathrm{J} / \mathrm{m}^{2}\right)\end{array}$} \\
\hline & & $\begin{array}{c}\text { Proportional } \\
\text { L1mit } \\
\left(\mathrm{MN} / \mathrm{m}^{2}\right)\end{array}$ & $\begin{array}{c}\text { Fracture Stress } \\
\left(M N / m^{2}\right)\end{array}$ & \\
\hline Single-Crystal** & 2.4 & & , & 0.54 \\
\hline $\begin{array}{l}\text { Single-Crystal } \\
\text { (Harshaw) }\end{array}$ & $1.6 \pm 0.3$ & $8.2 \pm 0.7$ & $12.21 \pm 3.8$ & \\
\hline $\begin{array}{l}\text { Single-Crystal } \\
\text { University of uian }\end{array}$ & $1.9 \pm 0.1$ & $5.6 \pm 0.6$ & $10.42 \pm 1.3$ & \\
\hline Press-Forged & & & & \\
\hline $\begin{array}{l}\mathrm{H}-20 \text { ( } 600 \mathrm{C}-63 \% \\
25 \mathrm{~m} \text { subgrains) }\end{array}$ & & $31.3 \pm 6.7$ & $53.8 \pm 11.7$ & $8.9 \pm 1.9$ \\
\hline $\begin{array}{l}\mathrm{H}-23(400 \mathrm{C}-54 \% ; \\
30 \text { m suletins) }\end{array}$ & & $46.3 \pm 3.7$ & $10.8 \pm 7.0$ & $11.0 \pm 3.8$ \\
\hline $\begin{array}{l}\text { U-1 ( } 500 \mathrm{C}-48 \% \\
30 \text { m subgrains) }\end{array}$ & $36.1 \pm 9.3$ & & & $7.8 \pm 1.4$ \\
\hline$U-4(500 C-62 \%)$ & $35.9 \pm 3.9$ & $38.3 \pm 3.7$ & $46.8 \pm 4.7$ & $8.87 \pm 2.02$ \\
\hline
\end{tabular}

*0. $2 \%$ of fset

**Reference 12 


\subsection{CRITICAL FRACTURE ENERGY}

The modified double-cantilever-beam technique described by Freiman et al.13 was used to determine the critical fracture energy, $\gamma_{c}$, of forged LiF. The critical fracture energy is the energy required to create a unit area of crack during rapid fracture. Specimens 2 to $3 \mathrm{~cm}$ in length, $\sim 1 \mathrm{~cm}$-wide and $0.5 \mathrm{~cm}$-thick were cut from forgings $\mathrm{U}-1, \mathrm{U}-4, \mathrm{H}-20$, and H-23 such that during testing, the crack ran parallel to the top and bottom surfaces of the forgings along a $0.2 \mathrm{~cm}$-wide groove whch was cut half-way through the thickness of each specimen. All fracture energy specimens were notched and sharp cracks, $\sim 1 \mathrm{~cm}$ long, were introduced in them by gently tapping a blade resting on the base of the notch. The tests were carried out in an Instron testing machine at a crosshead speed of 0.025 $\mathrm{cm} / \mathrm{min}$. Table 9 summarizes the measured $\gamma_{\mathrm{c}}$ 's, yield stresses in compression, and proportional limits and fracture strengths in three-point bending for both single-crystal and press-forged $\mathrm{LiF}$. These data indicate that press forging causes a substantial improvement in the mechanical properties of LiF. Yield stress and fracture energy are seen to have improved by more than a factor of ten, and proportional limit and fracture strength by as much as a factor of seven.

\subsection{MICROYIELD BEHAVIOR}

Strengths of alkali halides are usually measured in compression or in 3- or 4-point bending. In this context, proportional limit or yield strength corresponds to the stress at which the stress-strain curve is observed to deviate from linearity. Because of the difficulty encountered in determining precisely where the stress-strain curve deviates from a straight line, it is common to measure an offset yield strength at some small arbitrary plastic strain, usually 0.1 percent or 0.2 percent $(0.001$ or 0.002$)$.

Many materials can undergo plastic deformation at a fraction of their conventionally measured proportional limit or yield strength. This fact is of concern in the design of precision optical systems. In this connection the term microyield behavior is used to describe microplastic strain resulting from short duration loading, as in bending or compression tests carried out at moderate strain rates.

Microyield behavior of $\mathrm{LiF}$ has been studied in detail in this program. Samples used in this study were the same as those used to determine the effects of press forgings on the residual ultraviolet and visible absorption in $\mathrm{LiF}$, namely, $\mathrm{H}-30, \mathrm{H}-31, \mathrm{H}-38, \mathrm{H}-41, \mathrm{H}-42$ and $H<110>-4$. An identification mark corresponding to the trace of a $\{100\}$ plane was ground on the periphery of each boule and a section, $\sim 5 \mathrm{~mm}$-thick, was cut from it. The 
remainder of the boule was forged, using the forging parameters summarized in Table 1 . The $5 \mathrm{~mm}$-thick sections were cut to obtain single-crystal specimens for microstrain measurements. The orientation of each face of the specimens cut was $\{100\}$ in all cases except $\mathrm{H}-<110>-4$. The orientations of the various faces of the specimens cut from the $5 \mathrm{~mm}$-thick section of $\mathrm{H}-<110>-4$ boule are shown in Figure 16.

After we made calorimetric measurements on the six forgings used in this study, we cut them to obtain specimens for microstrain measurements. The cuts were made at an interval of about $2.5 \mathrm{~mm}$ parallel to the intersection of the identification mark on the surface (top or bottom) of the forgings in all cases except $\mathrm{H}-<110>-4$. In this case, the cuts were made perpendicular to the identification mark (i.e. parallel to the minor diagonal (see Figure 10).

Dimensions of the specimens for the study of microyield behavior were: thickness $\approx 2.5 \mathrm{~mm}$, width $\geq 5 \mathrm{~mm}$ and length $\geq 30 \mathrm{~mm}$. The specimens were mechanically polished and subjected to a series of load-unload cycles in 4-point bending using a distance of $1.91 \mathrm{~cm}$ between the supporting pins and $0.79 \mathrm{~cm}$ between the loading pins. The load on the specimen was increased incrementally in successive cycles using a crosshead speed of $0.0025 \mathrm{~cm} / \mathrm{min}$ to load the sample. The sample was unloaded as quickly as possible. After each cycle the permanent strain was measured by a bonded wire resistance strain gage which was attached to the specimen face subjected to the maximum tensile stresses.

Microyield behaviors of single-crystal and press-forged samples $\mathrm{H}-41$ are shown in Figure 17. Such data for all samples plotted in a straight line over a wide strain range on a log-log plot, as shown in Figure 18 and Figure 19.

Such straight lines were extrapolated to obtain $\sigma_{y}\left(10^{-6}\right)$, the yield stress corresponding to an offset strain of 10-6. Estimated $\sigma y(10-6)$ values for various $\mathrm{LiF}$ samples are summarized in Table 10 along with their proportional limit and fracture strength determined by conventional loading in 4-point bending at a crosshead speed of $0.0025 \mathrm{~cm} / \mathrm{min}$ to failure. These data indicate that the ratio of $\sigma_{y}(10-6)$ to the conventional proportional limit for $\mathrm{LiF}$ lies in the range $0.1-0.3$ and that the press forging can increase $\sigma_{\mathrm{y}}\left(1 \mathrm{U}^{-6}\right)$ of $\mathrm{LiF}$ by a factor of three to as much as a lacluir of ten (samples $\mathrm{H}-31$ and $\mathrm{H}-41$ ). 


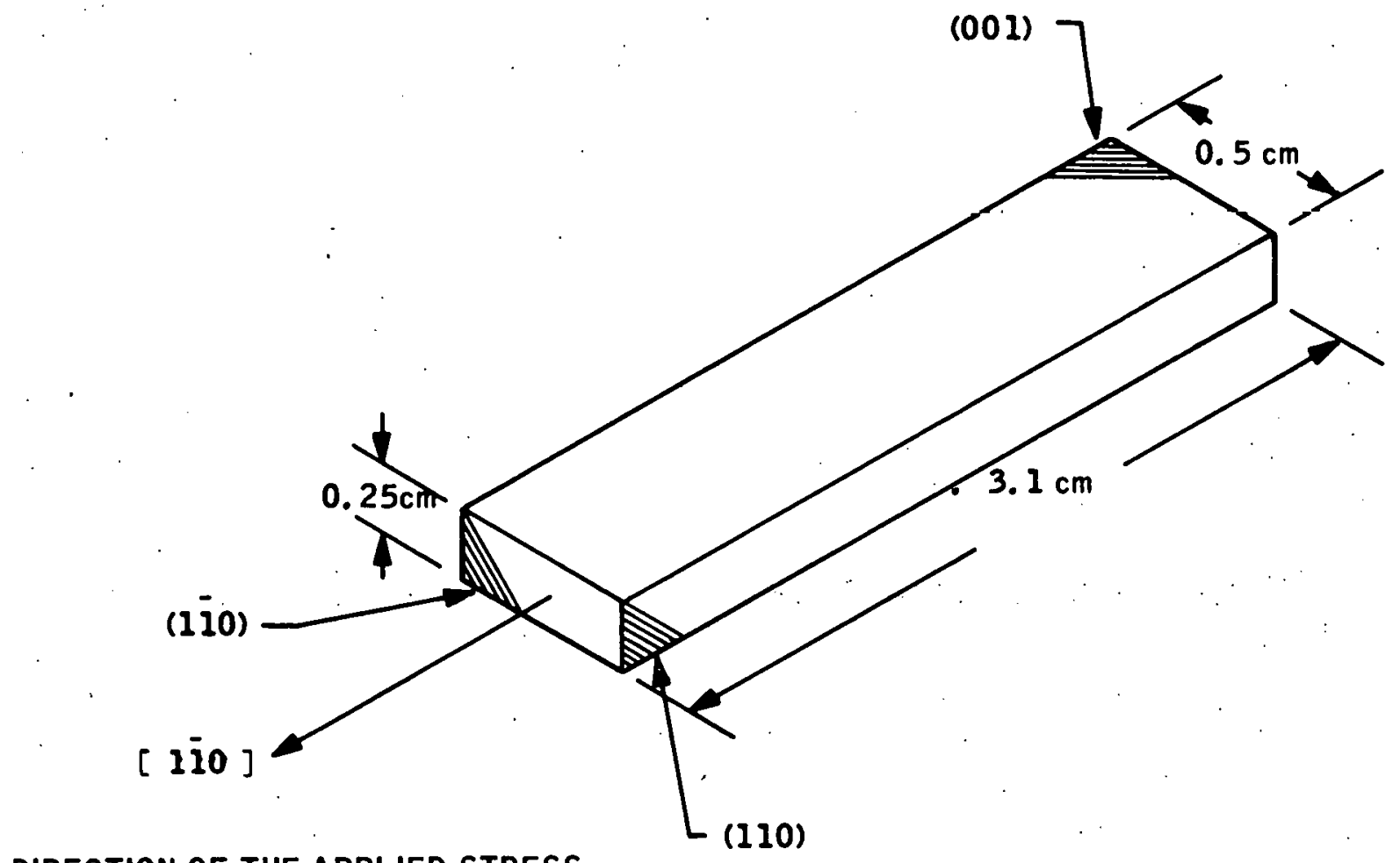

DIRECTION OF THE APPLIED STRESS

Figure 16. Orientation of 4-point bend specimen of singlecrystal $H-<110>-4$. 


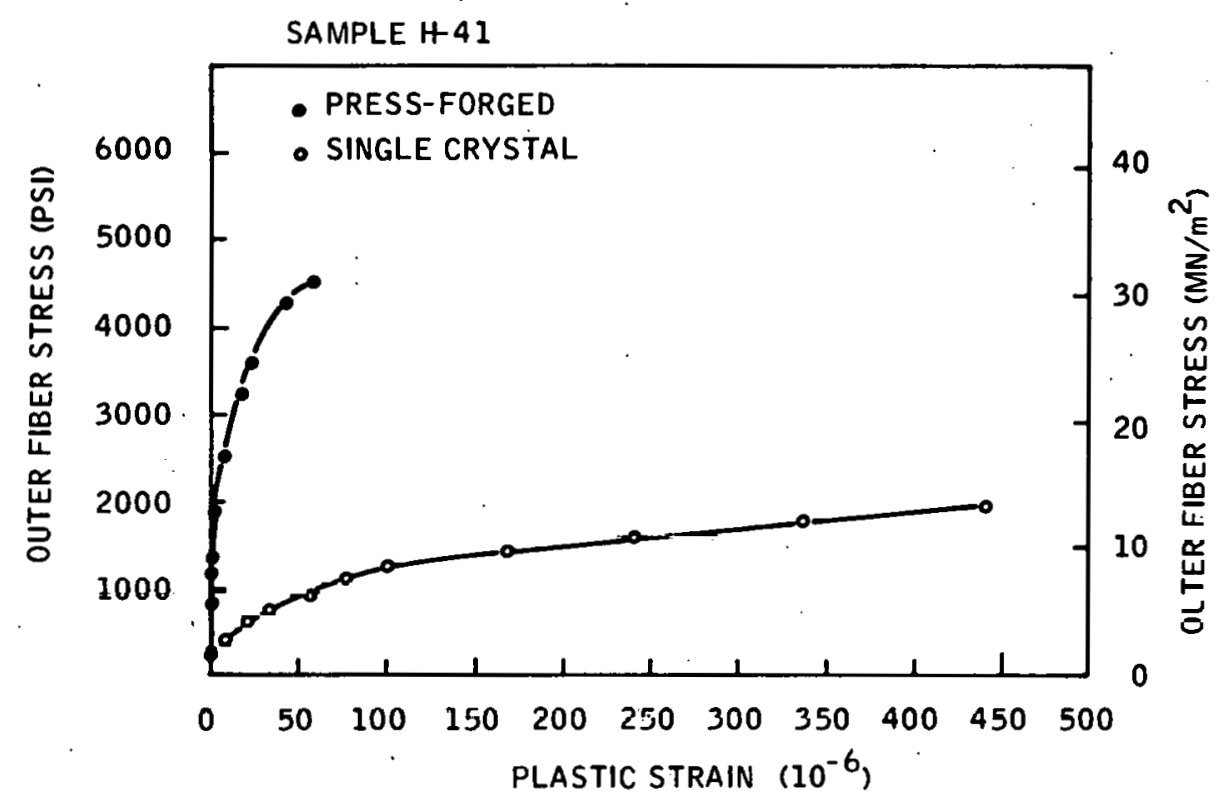

Figure 17. Microyield behaviors of single-crystal and press-forged samples $\mathrm{H}-41$.

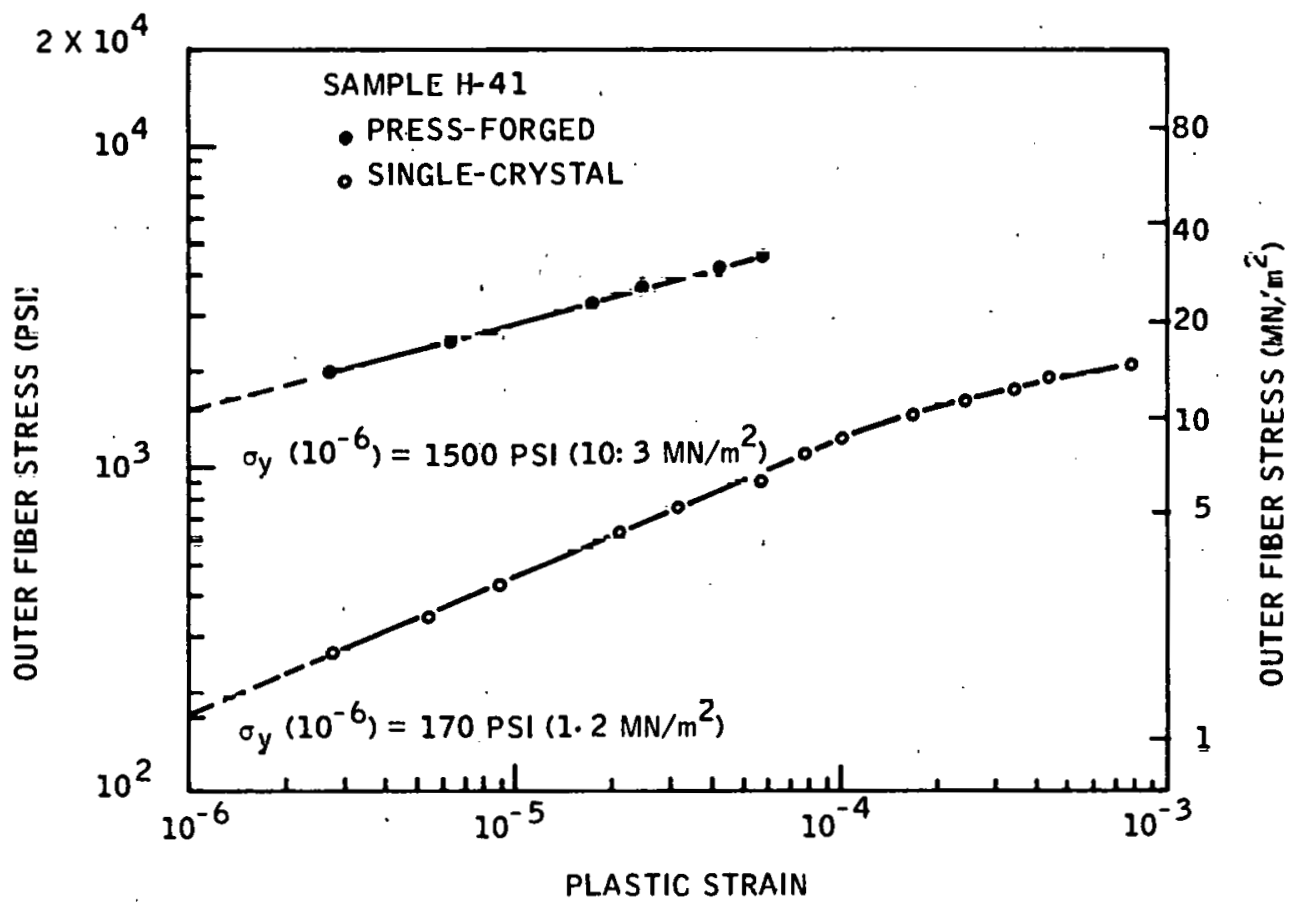

Figure 18. Log-log plot of the microyield data shown in Figure 17. 


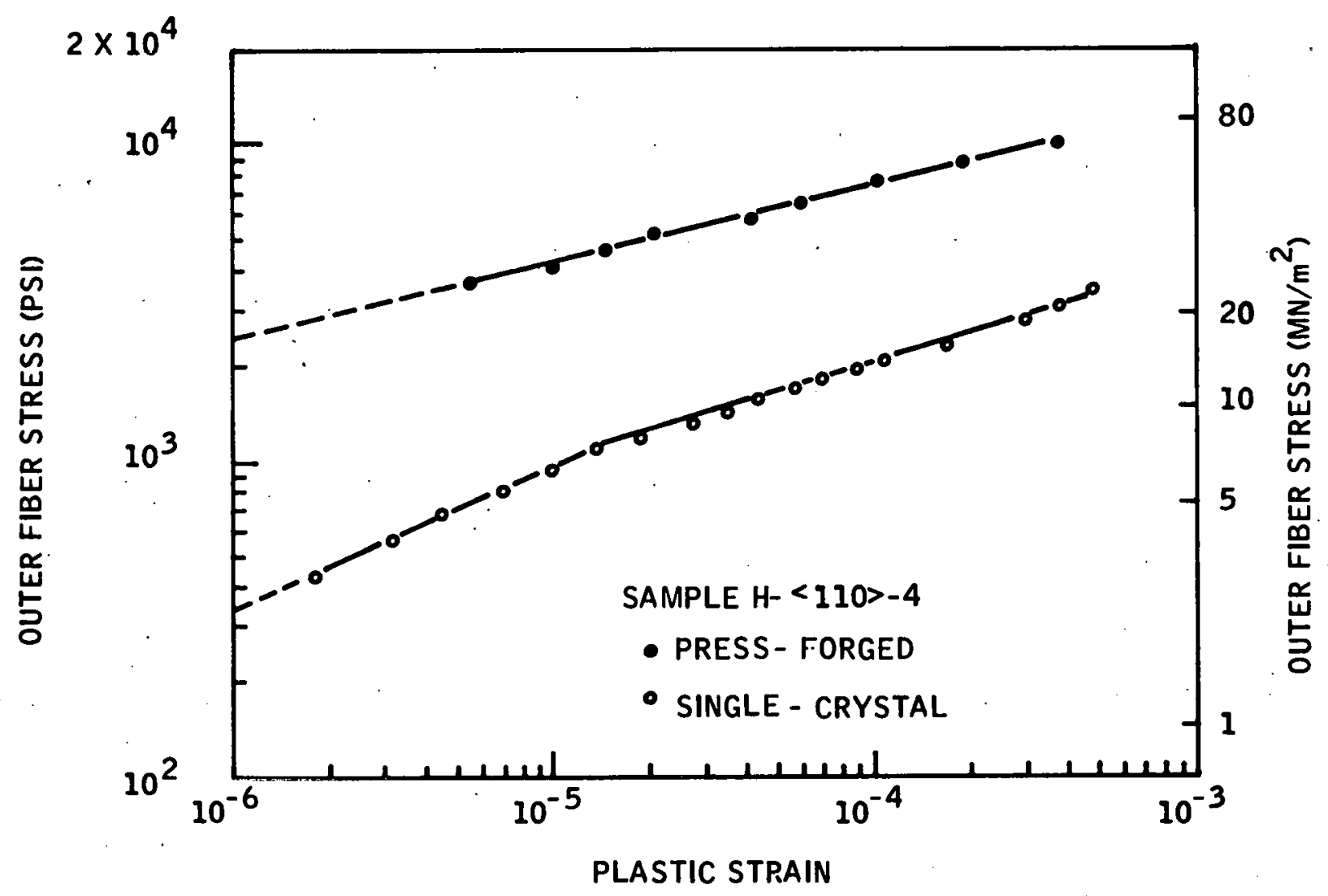

Figure 19. Microyield data of single-crystal and press-forged samples $H-<110>-4$ plotted on a log-log plot. 
Table 10. Microyield, Macroyield, and Fracture Characteristics of LiF.

\begin{tabular}{|c|c|c|c|c|c|}
\hline & Eample & \multirow{2}{*}{$\begin{array}{l}c_{y}\left(10^{-6}\right) \\
\left(4 N ; n^{2}\right)\end{array}$} & \multirow{2}{*}{\multicolumn{2}{|c|}{$\begin{array}{l}\begin{array}{l}\text { Conventional Proportional Lirit } \\
\left(\mathrm{MN}^{\prime} \mathrm{m}^{2}\right)\end{array} \\
251\end{array}$}} & \multirow{2}{*}{$\begin{array}{l}\begin{array}{c}\text { Fracture Strength, } \\
\left(\mathrm{MN} / \mathrm{m}^{2}\right)\end{array} \\
40.2\end{array}$} \\
\hline $\mathrm{H}-30$ & Press-Forjed & & & & \\
\hline \multirow{2}{*}{$\mathrm{H}-31$} & Single-Crystal & 0.33 & - & & - \\
\hline & Press-Forged & 8.27 & - & & - \\
\hline $\mathrm{H}-38$ & Fress-Forged & 3.72 & 34.01 & & 51.92 \\
\hline \multirow{2}{*}{$\mathrm{H}-41$} & Single-Crystal & 1.17 & 12.48 & & 18.31 \\
\hline & Press-Forged & 10.34 & 40.91 & & 51.82 \\
\hline$H-42$ & Press-Forged & 10.34 & 58.85 & & 64.48 \\
\hline \multirow{2}{*}{$H-\langle 110\rangle-4$} & Single-Crystal & 2.28 & 25.68 & & 40.02 \\
\hline & Press-Forged & 16.54 & 56.04 & & 63.15 \\
\hline
\end{tabular}


Note in Table 10 that the $\sigma_{y}(10-6)$ for the single-crystal sample $H-<110>-4$ is a factor of two or more greater than $\sigma_{y}(10-6)$ for the single-crystal samples H-41 and H-31. Much of this discrepancy is due to the fact that the direction of the applied stress during 4-point loading was [110] in the case of $\mathrm{H}-<110>-4$ crystal (see Figure 16) as compared to [100] in the other two cases. Since LiF slips on $\{110\}<110>$ slip systems, the application of stress in a $\langle 110\rangle$ direction results in a resolved shear stress on active slip systems which is half of that resulting from the stress application in a $<100\rangle$ direction. 


\section{Section 5 \\ Environmental Stability}

Press-forged crystals of many pure alkali halides may undergo grain growth or secondary recrystallization when aged at room temperature for a long period of time.14 These processes are accelerated if the relative humidity of the surrounding atmosphere is high. Such samples often show internal cloudiness which is not present in the as-forged crystals.

Press-forged $\mathrm{LiF}$ appears to be a very stable material under reasonable environmental conditions. Studies of the microstructures and scattering profiles of press forged LiF crystals before and after exposure to a relative humidity of 94 percent at $39^{\circ} \mathrm{C}$ for periods of up to five days show no increase in either grain size or optical scattering due to the exposure. In addition, periodic examinations of the microstructures of several press-forged LiF crystals exposed to ambient conditions of room temperature and relative humidity for periods of up to one year have not shown a significant increase in grain size. 


\section{Section 6 \\ Polishing Techniques}

As part of the contract work, polishing techniques for $\mathrm{LiF}$ were developed at the Honeywell Ceramics Center.

\subsection{SAWING}

One LiF single crystal was cut into three discs (samples for polishing) with a reciprocating slurry saw using 400 grit $\mathrm{SiC}$ abrasive. This sawing technique produced surfaces which were reasonably damage-free and prepared them for the shaping process.

\subsection{SAMPLE SHAPING}

Gross material removal from the faces and periphery of single crystal and forged LiF was performed with 500 grit alumina bonded to cloth. Single crystal samples were generally easy to shape by this method; however, the forged LiF blanks proved to be quite sensitive to stresses occurring during this operation. Fractures tended to form at the edges of forged blanks and continued to grow as grinding processed. Extreme care and gentleness was required to remove fractured areas and to continue removing material without generating new fractures.

\subsection{POLISHING}

Optical polishing methods were investigated for both single crystal and forged samples. Cerium oxide and 0.3 micron alumina were tested as polishing compounds. Beeswax and soft pitch were used as lap materials. The combination of 0.3 micron alumina and beeswax yielded the best surface finish on single crystal LiF. Cerium oxide consistently produced larger scratches, presumably due to an unacceptably slow rate of cerium oxide particle breakdown caused by the softness of LiF.

The 0.3 micron alumina-beeswax lap combination produced occasional grain pullouts when used for the polishing of forged LiF. Replacing beeswax with a soft pitch lap material remedied this problem on the samples having pullouts. On samples with no pullouts, beeswax was the preferred lap material due to fewer scratches.

Photomicrographs (200X) showing examples of polishing results obtained on forged $\mathrm{LiF}$ are shown in Figures 20 and 21. Figure 20 shows the scratch pattern obtained by the use of cerium oxide polishing compound. The much improved results obtained with 0.3 micron alumina are shown in Figure 21. 


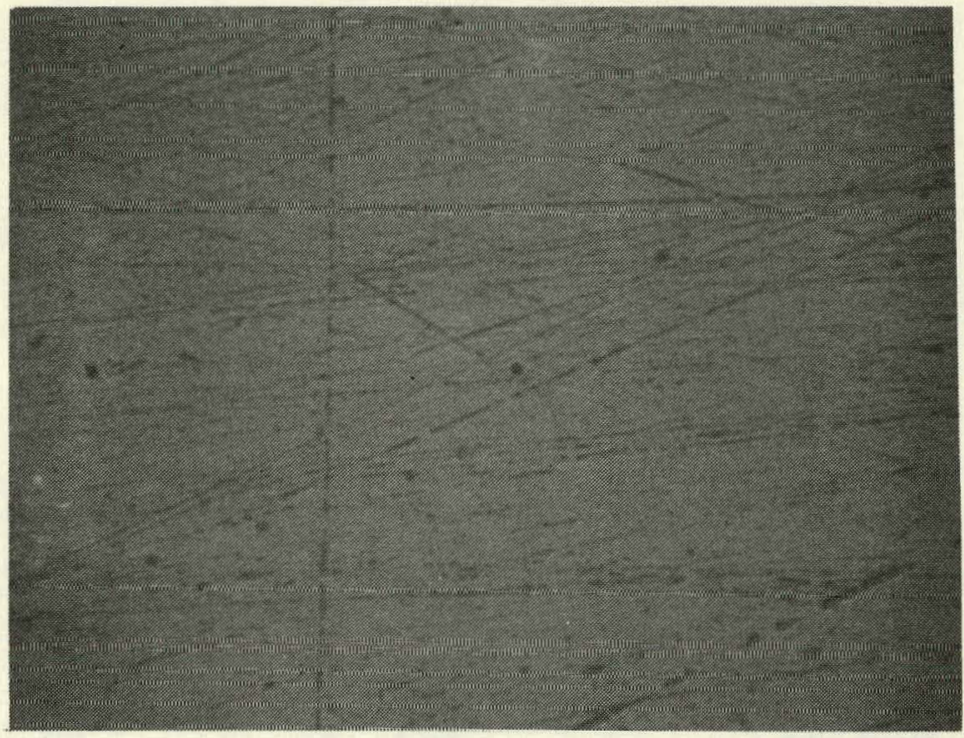

Figure 20. Forged LiF polished with cerium oxide (200X).

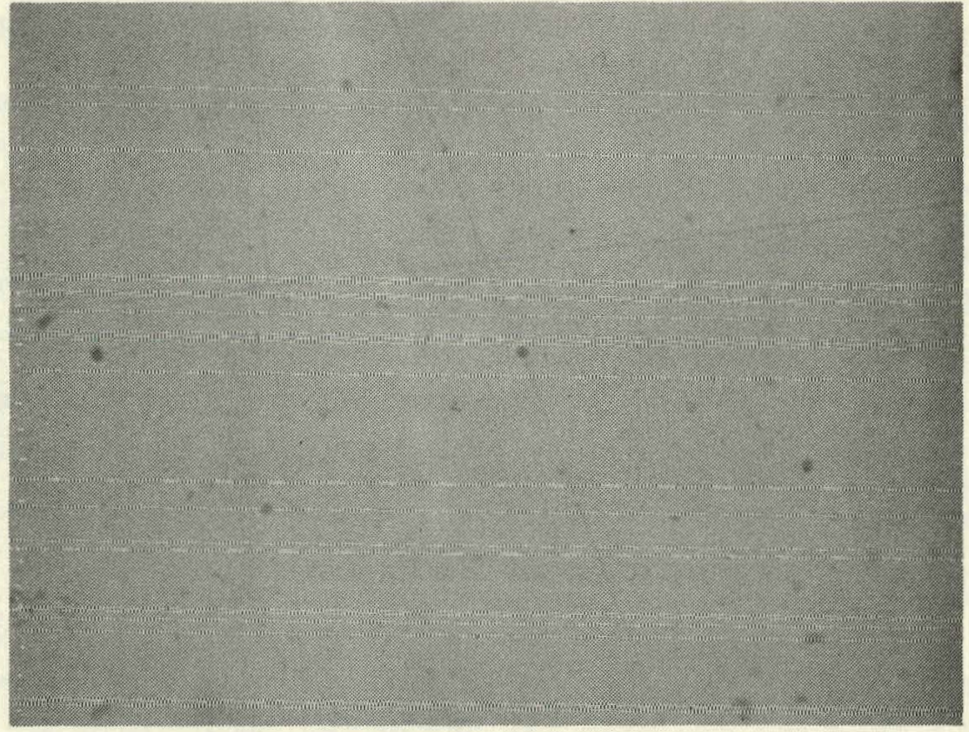

Figure 21. Forged LiF polished with $0.3 \mu \mathrm{m}$ alumina. 


\section{Section 7 \\ Forging of $\mathrm{KTb}_{3} \mathrm{~F}_{10}$}

During the course of this program, a sample of $\mathrm{KY}_{3} \mathrm{~F}_{10}$ and a batch of four $\mathrm{KTb}_{3} \mathrm{~F}_{10}$ samples were delivered to Honeywell by Sanders Associates, Inc. Attempts were made to press forge only $\mathrm{KTb}_{3} \mathrm{~F}_{10}$ in this program. The samples of $\mathrm{KTb}_{3} \mathrm{~F}_{10}$ delivered are shown in Figure 22. These samples were numbered 1 through 4 . Samples $1-3$ were about $2.5 \mathrm{~cm}$ in height, contained twins, grain boundaries and numerous fine cracks, and appeared to be fragments of a boule of circular cross-section with diameter varying along the growth direction (average diameter $2.5 \mathrm{~cm}$ ). Sample 4 was approximately $1.5 \times 1.2 \times 0.6 \mathrm{~cm}$ in size and fractured when attempts were made to cut and polish it for scattering measurements.

In order to obtain specimens for metallographic examination and for press forging, sample 1 was cut into three sections along transverse planes using a diamond cutting wheel. Metallographic examination of one section, which was polished and etched in boiling concentrated nitric acid*, revealed the presence of a twin and what appeared to be microcracks or second phase precipitates (see Figures 23 and 24). Another section of $\mathrm{KTb}_{3} \mathrm{~F}_{10}$ sample 1 fractured into two subsections by propagation of a radial crack during polishing. Attempts were made to forge one subsection at $400^{\circ} \mathrm{C}$ and the other at $700^{\circ} \mathrm{C}$ using a displacement rate of $0.013 \mathrm{~cm} / \mathrm{min}$ and a $13.8 \mathrm{mn} / \mathrm{m}^{2}$ helium environment. In both cases, the subsections disintegrated into numerous small fragments.

A specimen about $1 \mathrm{~cm}$ in height was later cut from $\mathrm{KTb}_{3} \mathrm{~F}_{10}$ sample 2 and polished. Back-reflection Laue photographs taken from various locations indicated the presence of more than one grain boundary in the specimen. An attempt was made to forge this specimen at $810^{\circ} \mathrm{C}$ along with a LiF crystal of comparable height. The $\mathrm{KTb}_{3} \mathrm{~F}_{10}$ specimen disintegrated during forging. The recovered fragments in this case were observed to be much larger in size than those of the previous two cases. Measurements of the thickness (before and after forging) of the $\mathrm{LiF}$ crystal indicated that the $\mathrm{KTb}_{3} \mathrm{~F}_{10}$ specimen disintegrated before reaching a deformation level of $\sim 25$ percent reduction in height.

A part of $\mathrm{KTb}_{3} \mathrm{~F}_{10}$ sample 4 was ground into powder and its $\mathrm{x}$-ray diffraction pattern was examined. All diffraction lines except three, which corresponded to d-spacings of 5.9, 3.4 and $2.7 \AA$, could be indexed assuming an f.c.c. cell of $11.64 \AA$ lattice parameter.

\footnotetext{
*The etchant was suggested to us by Dr. David Gabbe of the Massachusetts Institute of Technology.
} 


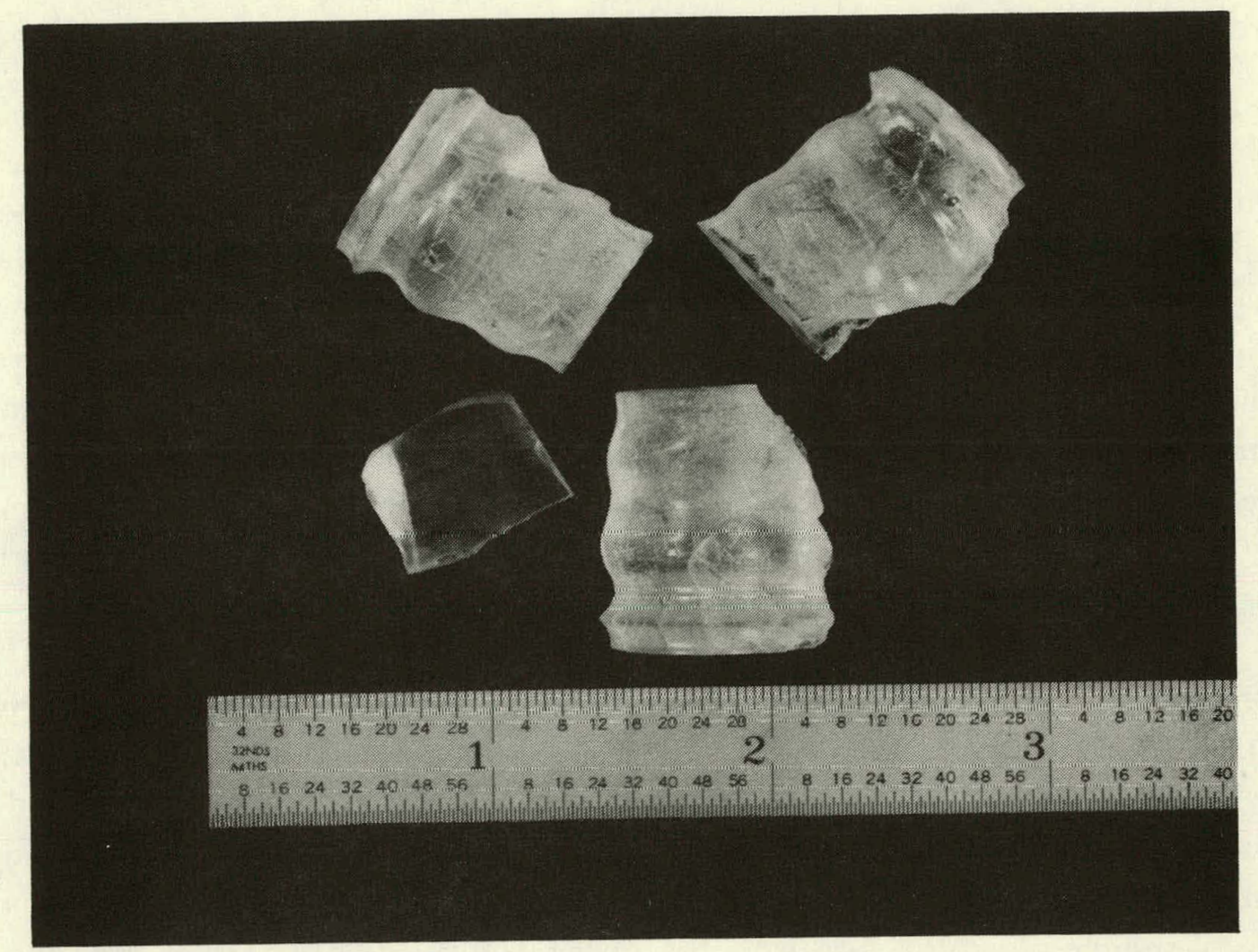

Figure 22. Samples of $\mathrm{KTb}_{3} \mathrm{~F}_{10}$. 


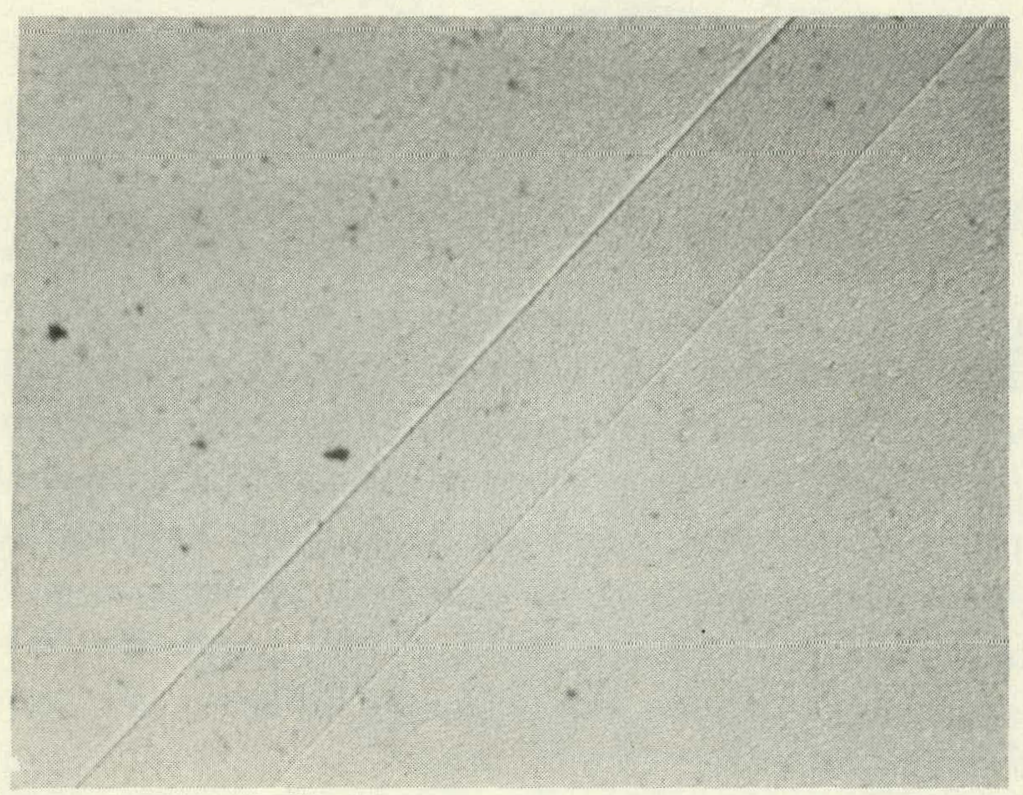

Figure 23. Photomicrograph of an etched sample of $\mathrm{KTb}_{3} \mathrm{~F}_{10}$ showing a twin (120X).

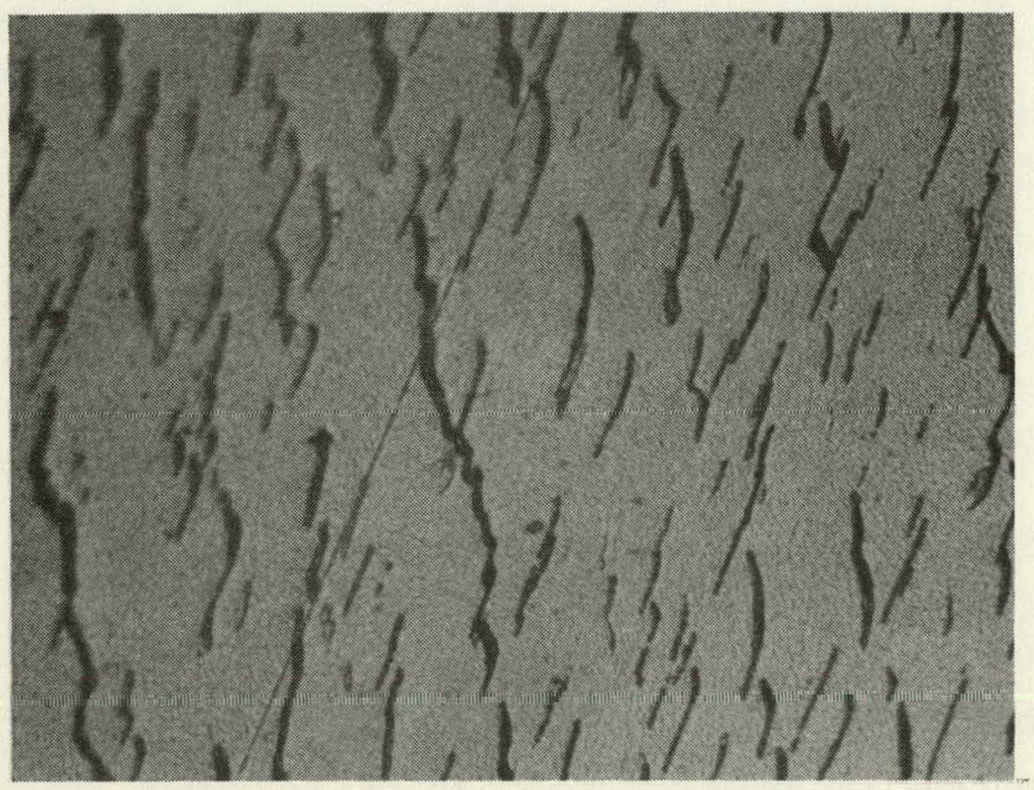

Figure 24. Photomicrograph of an etched sample of $\mathrm{KTb}_{3} \mathrm{~F}_{10}(60 \mathrm{X})$. 


\section{Section 8 \\ Summary}

Studies of the response of $\mathrm{LiF}$ crystals to press forging indicate that they are susceptible to veiling at large deformation. Using a two-step forging approach, a significant reduction in the degree of veiling has been achieved in crystals forged to reductions of 75 percent. Forged LiF crystals have been shown to possess stable microstructure which is not changed by aging in ordinary ambient environments or after exposure to an atmusphere of high rclative humidity. Measurements of the mechanical and optical properties of both single-crystal and press-forged LiF indicate that the press forging brings about a substantial improvement in the mechanical properties of LiF without significantly degrading its excellent optical properties. 


\section{Acknowledgements}

The authors wish to thank Drs. D. Milam, T.F. Deaton and W.L. Smith of Lawrence Livermore Laboratory for performing the measurements of laser damage threshold, and Dr. Nils Fernalius of the University of Dayton Research Institute for providing the infrared absorption data. The authors also wish to thank Clark Olson, Dick Brinda, Mark Paquette, Don Parkin and Dave Woodward for providing capable technical assistance in performing the press forging and experimental measurements, and R.A. Skogman for his association with this project in its early stages. 


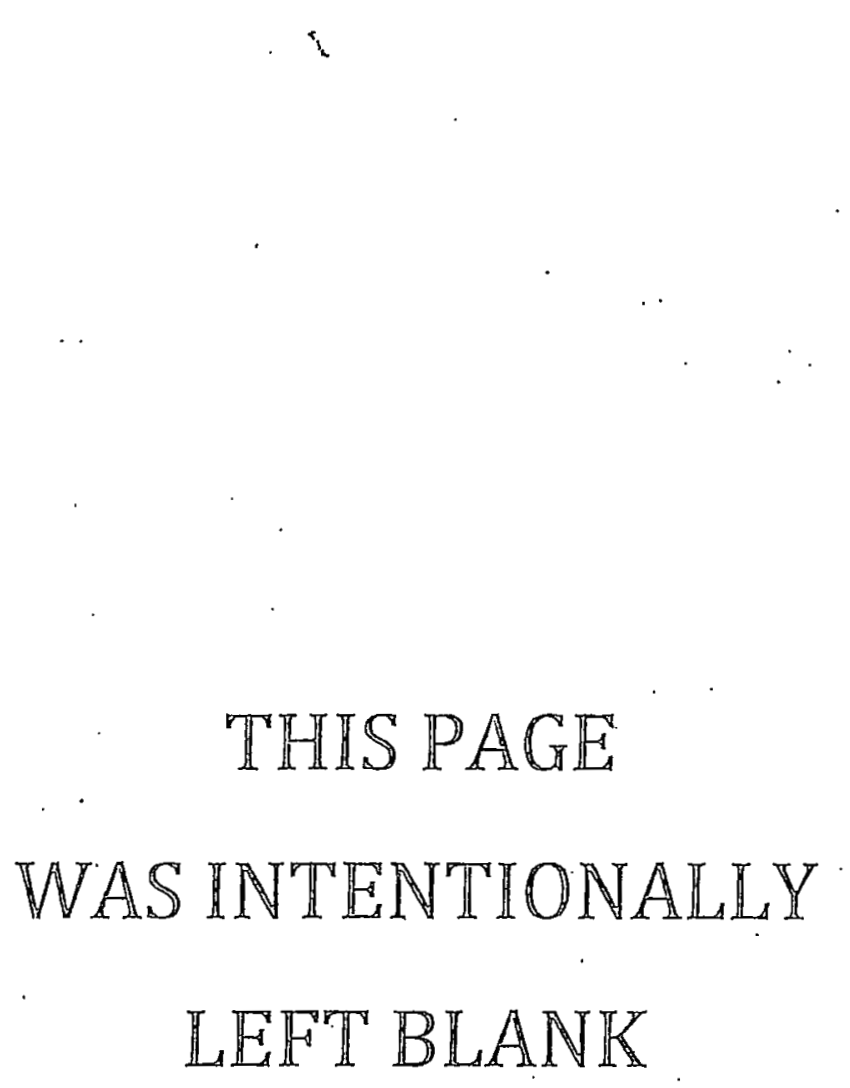




\section{References}

1. M.J. Weber, D. Milam, and W.L. Smith, Opt. Eng. 17, 463 (1978).

2. E. Bernal G., B.G. Koepke, R.J. Stokes and R.H. Anderson, Proceedings of Conference on High Power Infrared Laser Window Materials (October 30 November 1, 1972), Bedford, Mass., Carl A. Pitha, Ed., p. 413 (1973). Air Force Cambridge Research Laboratories, AFCRL-TR-73-0372.

3. R.H. Anderson, R.A. Anderson, and H. Vora, Opt. Eng. 18, 602 (1979).

4. J.J. Gilman, Acta Met. 7, 608 (1959).

5. G.W. Groves and A. Kelly, Phil. Mug. 8, 877 (1963).

6. W.L. Phillips, Jr., AIME Trans. 218, 947 (1960).

7. American Institute of Physics Handbook, Third Edition, McGraw Hill, New York, 1972, p. 9-17.

8. H.E. Bennett, J.W. Bethke, and W.P. Norris, Proceedings of the High Power Laser Optical Components and Component Materials Meeting, October 3-4, 1977, Boulder, Colorado, compiled by J.S. Harris and C.L. Strecker (Defense Advanced Research Projects Agency, Arlington, Virginia, 1977), p. 327.

9. E. Bernal G., K.M. Leung, and J.S. Loomis, Interferometric Testing and Analysis of Windows Exposed to $\mathrm{CO}_{2}$ Laser Irradiation, Final Technical Report for Navy Contract N605-30-77-W-6511, May 20, 1977.

10. J.W. Dally and W.F. Riley, Experimental Stress Analysis, McGraw-Hill Book Co., New York (1965).

11. T.F. Deaton and W.L. Smith, in Laser Induced Damage in Optical Materials: 1979, A.J. Glass and A.H. Guenther, Eds. To be published as an NBS Special Publication.

12. C.N. Ahlquist, Acta Met. 22, 1133 (1974).

13. S.W. Freiman, D.R. Mulville, and P.W. Mast; J. Mater. Sci. 8, 1527 (1973).

14. B.G. Koepke, R.H. Anderson, E. Bernal G., and R.J. Stokes, J. Applied Physics 45, 969 (1974). 


\section{THIS PAGE}

WAS INTENTIONALLY

LEFT BLANK 


\section{Distribution List}

Dr. Owen Lewis

Office of Laser Fusion C404. U.S. Department of Energy Washington, D.C.

U.S. Dept. of Energy (3 copies) Technical Information Center P.0. Box 62

Oak Ridge, TN 37830

Mr. Rox Purcell (1 copics) U.S. Department of Energy Nevada Operations Office Las Vegas, NV 89114

Mr. Daryl B. Morse U.S. Department of Energy Nevada Operations Office Las Vegas, NV 89114

Dr. Marvin J. Weber Lawrence Livermore Laboratory Post Office Box 5508

Livermore, CA 94550

Dr. Steven Jacobs University of Rochester Laboratory for Laser. Energetics River Station, Hopeman 110 Rochester, NY 14627

Mr. Sandy Thomas KMS Fusion, Inc. 3941 Research Park Drive Post Office Box 1567

Amn Arbor, MI 48106

Professor John D. Mackenzie UCLA 405 Hilguard

Los Angeles, CA 90024

Mr. John McMahon Naval Research Laboratory Code 6730

Washington, D.C. 20375
Dr. Stanley Stokowski

Lawrence Livermore Laboratory Post Office Box 808 Livermore, CA 94550

Dr. John L. Emmett Lawrence Livermore Laboratory Post Office Box 5508 Livermore, CA 94550

Dr. Gerald E. Blair Department 144 Hawkeye Works Eastman Kodak Rochester, NY 14650

Dr. Morris Braunstein Chemical Physics Department Hughes Research Laboratory 3011 Malibu Canyon Road Malibu, CA 90265

Mr. Robert J. Ginther Naval Research Laboratory Washington, DC 20375

Mr. Paul Lovoi ILC Technology 164 Commercial Street Sunnyvale, CA 94086

Capt. Harvey Winsor Defense Advanced Research Projects Agency 1400 Wilson Boulevard Arlington, VA 22209

Dr. James Swingle Lawrence Livermore Laboratory P.O. Box 5508 Livermore, CA 94550

Mr. Evan Chicklis Defensive Systems Division Sanders Associates 95 Canal Street Nashua, NH 03060 
Dr. John Holzrichter Lawrence Livermore Laboratory Post Office Box 5508 Livermore, CA 94550

Dr. W.K. Haller, Chief Inorganic Glass Section National Bureau of Standards Washington, DC 20234

Dr. Roger B. Perkins L Division Leader Los Alamos Scientific Laboratory Post Office Box 1663 Los Alamos, NM 87545

Mr. Joseph Clayton KMS Fusion Inc. 3911 Research Park Dr. P.O. Box 1567

Ann Arbor, MI 48106

Dr. James Gerado Fusion Program Los Alamos Scientific Laboratory P.O. Box 1663

Los Alamos, NM 87545

Dr. Arthur H. Guenther AFWL/CA

Kirkland AFB, NM 87115
Dr. E.V. George

Dr. W.L. Smith

Dr. David Milam

Dr. T.F. Deaton

Dr. W.F. Krupke

Dr. Howard Lowdermilk

Lawrence Livermore Laboratory

P.O. Box 5508, L465

Livermore, CA 94550

Dr. Brian Newnam

Los Alamos Scientific Laboratory

P.O. Box 1663, MS 564

Los Alamos, NM 87545

Dr. R.J. Stokes

Dr. G.]. Tong

Mr. E.L. Stelzer

Mr. R.H. Anderson

Dr. T.J. Moravec

Mr. E. Bernal G.

Honeywell Corporate Technology Center 10701 Lyndale Ave. S.

Bloomington, MN 55420

Mr. William B. Harrison

Dr. Regis Betsch

Mr. Vincent Shymanski

Honeywell Ceramics Center

1885 Douglas Dr. No.

Minneapolis, MN 55422 